\title{
Exotic Optical Fibers and Glasses: Innovative Material Processing Opportunities in Earth's Orbit
}

\author{
loana Cozmuta ${ }^{1}$ and Daniel J. Rasky ${ }^{2}$ \\ ${ }^{1}$ Science and Technology Corporation, Space Portal, NASA Ames \\ Research Center, Moffett Field, California. \\ ${ }^{2}$ Space Portal, NASA Ames Research Center, Moffett Field, \\ California.
}

\section{ABSTRACT}

Exotic optical fibers and glasses are the platform material for photonics applications, primarily due to their superior signal transmission (speed, low attenuation), with extending bandwidth deep into the infrared, exceeding that of silica fibers. Gravitational effects (convection sedimentation) have a direct impact on the phase diagram of these materials and influence melting properties, crystallization temperatures, and viscosity of the elemental mix during the manufacturing process. Such factors constitute limits to the yield, transmission quality, and strength and value of these fibers; they also constrain the range of applications. Manufacturing in a gravity-free environment such as the Earth's Orbit also helps with other aspects of the fabrication process (i.e., improved form factor of the manufacturing unit, sustainability). In this article, revolutionary developments in the field of photonics over the past decade merge with the paradigm shift in the privatization of government-owned capabilities supporting a more diverse infrastructure (parabolic, suborbital, orbital), reduced price, and increased frequency to access space and the microgravity environment. With the increased dependence on data (demand, bandwidth, efficiency), space and the microgravity environment provide opportunities for optimized performance of these exotic optical fibers and glasses underlying the development of enabling technologies to meet future data demand. Existing terrestrial markets (Internet, telecommunications, market transactions) and emerging space markets (onorbit satellite servicing, space manufacturing, space resources, space communications, etc.) seem to converge, and this innovative material processing opportunity of exotic optical fibers and glasses might just be that "killer app": technologically competitive, economically viable, and with the ability to close the business case.

Keywords: exotic optical fibers and glasses, ZBLAN, microgravity, space technology, orbital manufacturing, photonics, terrestrial applications, innovation, market analysis, economic viability, killer app, space markets

\section{INTRODUCTION}

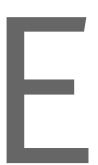

xotic optical fibers and glasses are the platform material for photonic applications, indispensable of everything from medical device technology to data telecommunications.

In 2013, the global photonics market was valued at \$509.7 billion US Dollars (USD), with a steady Compound Annual Growth Rate (CAGR) of 5.8\% between 2014 and $2020 .^{1}$ The propelling force behind this growth was attributed to an increased demand for electronic products and an exponential increase in the volume of data in a constant process of transfer. The fastest growing segment was identified as being driven by the medical and healthcare industry.

A more recent survey reports an estimated CAGR of $8.4 \%$ between 2016 and 2021, predicting that the global photonics market size will reach 724.22 billion USD by $2021 .^{2}$

The terrestrial global market is driven by increasing demand in almost every area of the global industry: consumer electronics; safety and defense; metrology; sensing; highperformance computing; building and construction; media and broadcasting; information and communication technology; telecommunication; market transactions; healthcare; agriculture; oil industry; medical and healthcare, etc. The driver applications cover a broad spectrum from medical technology and life sciences, measurement and automated vision, lighting and production technology, displays, Internet hardware, and infrastructure.

For example, in the information technology, telecommunication, and market transaction segments, the demand for

(c) Ioana Cozmuta and Daniel J. Rasky 2017; Published by Mary Ann Liebert, Inc. This is an Open Access article distributed under the terms of the Creative Commons Attribution License, which permits unrestricted use, distribution, and reproduction in any medium, provided the original work is properly cited. 
photonics is driven by needs for data conversion, modulation and amplification (optical modulators, optical interconnects, photo detectors, etc), data storage (hard drives, servers), and data transmission (fiber optic cables, lasers, wavelength division multiplexer filters, waveguides, etc.).

New technological gaps emerge continuously due to the fast-paced, steady growth (estimated to about a factor of 100 for every past decade) of the Internet, which has transformed society from simple personal interactions to broader business practices. Reliance on the Internet is projected to be even heavier than before, which drives new demands such as significant increases in bandwidth, network capacity, and flexibility. Assuming the same factor of growth over the next decade, it has been identified that several existing technologies are close to or have reached their limits. This has become a big barrier inhibiting the desired progress and highlights the need to invent new technologies (transmission, amplification, and switching) for the next cost-effective capacity increase in long distance, metropolitan, and local-area optical networks.

Health-related photonics advancements constitute another area where the optics and photonics community is actively developing new methods and technologies for sensing, imaging, and metrology such as instrumentation to allow not only simultaneous, high-resolution and high-capacity imaging and measurements, increased sensitivity and specificity of molecular detection but also safer and more rapid development of new pharmaceutical drugs.

Three economic sectors in which optical fibers and associated fiber lasers have found important applications ${ }^{3}$ are:

- Transportation (\$1 trillion estimated output during 2009-2010);

- Biomedical (\$2.5 trillion); and

- Telecommunications, e-commerce, and information technology ( $\$ 4$ trillion).

The lasers deployed in each of these 3 sectors contributed to the overall market by $\$ 1.3$ billion (CO2 and fiber), $\$ 400$ million (solid-state and excimer lasers), and $\$ 3.2$ billion (diode and fiber lasers), respectively.

Interesting to highlight are also emerging technology areas that could change our daily lives in the future: eyeimplantable electronic imaging devices aimed at restoring sight to the blind; versatile, cost-effective, laser-based, desktop three-dimensional object printing; single-photon-based integrated circuits; optical and hybrid optical-photonic interconnects, for dramatic increase in power efficiency and speed; smartphone or smartwatch flexible displays; rollout, flexible display for holographic communication; and mobile, high-speed, high-accuracy lasers for instant neutralization of threats. On the horizon, exotic optical fibers could be considered the enablers not only for quantum communication and quantum computing (one of the known current difficulties is the need to convert quantum information to be transmitted over silica fibers) but also for laser-driven light sail schemes such as the Breakthrough StarShot (https://break throughinitiatives.org/Initiative/3) privately funded initiative.

To meet these growing global demands, several overarching grand challenges emerge: the development of more efficient electronic products (less power consumption); more costeffective capacity increase for optical networks; low-cost fabrication and packaging of electronic components; highresolution and high-fidelity imaging and surveillance optical technologies; increased resolution in manufacturing; higher bandwidth; higher speed of communication and transmission, etc. The demand is pushing the technological needs, which, in turn, rely on innovative, higher performance, next generations of materials and metamaterials.

Even more interesting is the realization and acknowledgment that "the staggering ubiquity of information today, which is carried globally and almost instantaneously via optical fibers, is enabled largely by one material-silica-into which only a few components are added. The richness of the Periodic Table has largely been forgotten...."3

Naturally, following the value chain of the photonics market (starting from the sourcing of basic raw materials, manufacturing, and supplying to intermediate product manufacturers for the various end-use applications), it is interesting to note that the push for the developments mentioned earlier with regard to materials for optics and photonics applications, including the area of metamaterials, unveils a critical reliance and need on certain raw materials such as Iridium, Platinum, Rhodium, Silver, Osmium, Lantanium, Zinc, Germanium, Rhenium, Tungsten, Tin, etc. ${ }^{2}$

The standard fiber optics technology today relies on silica due to its abundance in the Earth's crust, easy processing and manufacturing, considerations that are important to the affordability of the product. An optical fiber is a flexible, transparent fiber that is made of high-quality extruded glass or plastic, and it is slightly thicker than a human hair. It acts as a conduit to carry a signal or light from one point to another at close to the speed of light. Fibers are increasingly replacing metal wires because signals travel along them with less loss and they are immune to electromagnetic interference. Optical fibers can be used as either a single fiber or bundled together. They can function as waveguides to transmit light between the 2 ends of the fiber (Fig. 1). Each fiber can carry many independent channels, with each channel using a different wavelength of light for transmission. 


\section{TERRESTRIAL MARKETS AND MATERIAL PROCESSING IN EARTH'S ORBIT}

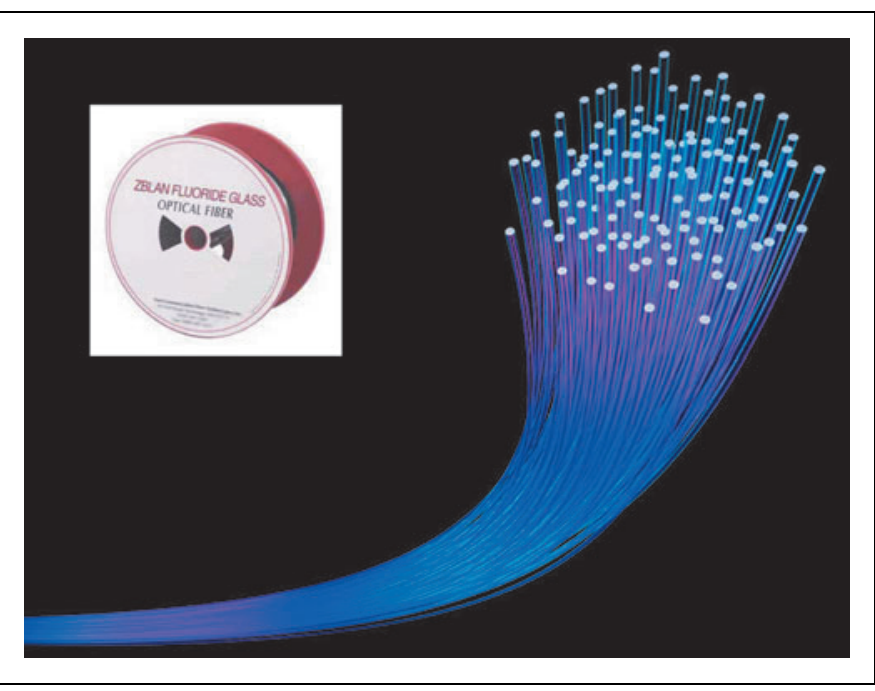

Fig. 1. Images of a spool with exotic optical fiber spool (left) and bundle of exotic optical fiber (right). (Sources: Thorlabs, Fiber Optics)

Exotic glasses are made from a complex formulation of materials, including metal fluorides and rare earth elements, which can be melted together in a wide range of combinations and drawn into optical fibers for different applications. Exotic optical fibers are used to transmit signals, create lasers and laser scalpels, act as sensors and lenses, enable telecommunications and high-speed computer applications, and provide imaging capabilities in hard-to-reach areas, including inside the human body.

Exotic glasses such as ZBLAN and other fluoride glasses can be doped with a number of rare earth ions for application in fiber lasers and amplifiers. Fiber lasers can be used for marking, engraving, cutting, telecommunications, surgery, and military applications. ${ }^{2}$ Supercontinuum sources (fiber laser sources with very broad bandwidths) enable tuning for use as chemical hazard sensors and other research and medical applications or can replace or reduce the number of separate lasers or light sources used to span a wide bandwidth. ${ }^{2}$

There are many challenges in meeting the requirements identified earlier, that is, high resolution, high bandwidth, and high transmission capacity. At a material level these requirements translate into the need for more uniform, defect-free structures, improved structure-property correlation for controlled material design. The equilibrium state and limits of stability of the various phases in a chemical system at equilibrium are dependent and defined by variables such as composition, temperature, pressure, etc. Gravity, however, is a "hidden" variable underlying the fine points of such phase diagrams, and very few academic or industrial researchers think of gravity phenomena that, ultimately, limit the system's performance (Fig. 2). Thus, the wide majority of research groups approach these challenges terrestrially while being unaware or having little knowledge of microgravity-fueled advances. When the force of gravity is removed, other forces (surface tension, capillary forces, etc.) become the drivers of the overall system dynamics.

Microgravity or reduced gravity represents a 6 order of magnitude reduction in one of the fundamental forces, gravity.

Spaceflight research was established first in 1946 through a study of the cosmic radiation on a U.S. V2 rocket. This continued to develop between 1947 and 1961 through a series of "first" experiments in space and microgravity: from the "first" animals into space (i.e., fruit flies, U.S. V2), to the "first" animal into the orbit (the dog Laika on USSR Sputnik 2), to the "first" plants and animals to return alive from the Earth's orbit (USSR, Sputnik), and culminating with the April 12, 1961 first human spaceflight of Yuri Gagarin on USSR Vostok I. From a materials perspective, 1969 represented the year of the first welding experiment in space on Soyuz 6; 1971 indicated the composite casting on Apollo 14. Between 1973 and 2000, a wealth of microgravity experiments were conducted using specialized equipment, such as the Materials Processing Facility and the Multipurpose Furnace System. Such equipment was installed on Skylab (1973-1979), Space Hub and Space Shuttle (1980-2000) and the first USSR space stations (Salyut I, MiR). Today, through international collaboration, the International Space Station represents a multinational platform for microgravity and space research.

Research in the microgravity environment in the Low Earth Orbit has furthered our understanding of fundamental physical, chemical, and biological processes and generated a wealth of results in areas such as material science, combustion science, fluid physics, fundamental physics, life science, and biotechnology. Physical phenomena such as glass formation, crystallization, capillary and multiphase flow, surface tension, heat transfer, phase transition, and containerless processing have been identified as importantly different in microgravity in a manner that could be important to manufacturing new products or advancing new technologies on Earth (Fig. 2).

This article is focused on exploring the significance of the reduced gravity environment to investigate the impact of gravity-driven effects on material properties (attenuation and reflectivity) and processing (fiber drawing, microgravity preform reprocessing, microgravity manufacturing of glasses and preforms) that are relevant to exotic optical fibers.

Despite their promise, the performance of exotic optical glasses and fibers is still far from the "theoretical absolute." 


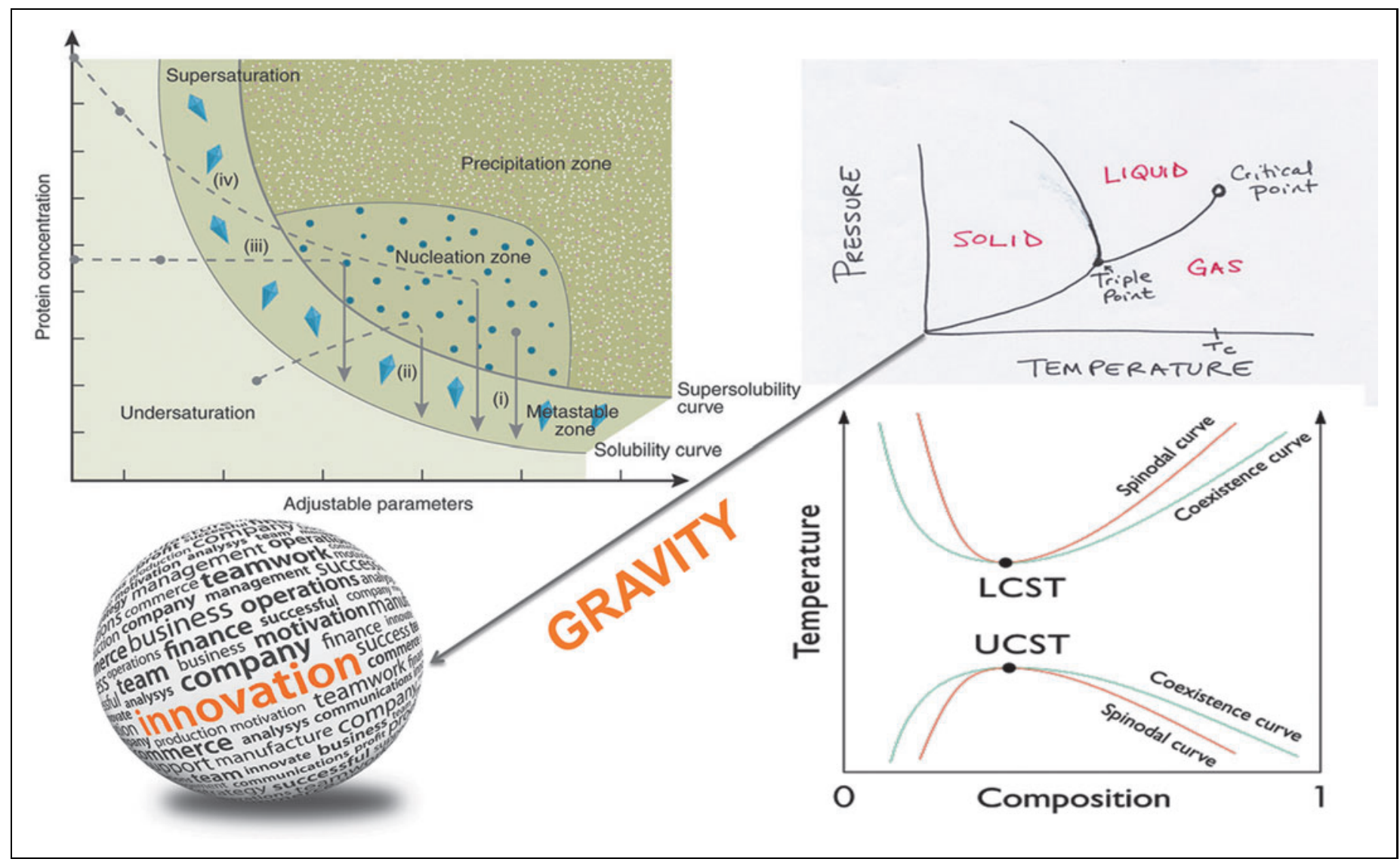

Fig. 2. Gravity represents a new variable/axis on system's phase diagrams (top right), whether for material science applications or soft matter, that is, protein crystallization (top, left) or binary colloids (bottom right). The exploration of new environments historically is an engine for innovation and new discoveries. (Sources: Wikipedia, Nature Methods)

Current performance limits the yield, transmission quality, strength, and value of these fibers and, more importantly, constrains the range of applications that can be developed from them. Gravitational effects such as convection and sedimentation have a direct impact on the phase diagram of all the members of the exotic optical fibers and glasses. Gravity influences melting properties, crystallization temperatures, and viscosity of the elemental mix during the manufacturing process. Another key underlying reason for this limitation is represented by impurities in the fibers manufactured on ground. One potential solution to this problem is on-orbit manufacture, where the microgravity environment minimizes many of these effects. Another possibility that on-orbit manufacturing opens up is the fabrication of hollow optical fibers, multilayered optical fibers, and control of the doping process. Manufacturing in the Low Earth Orbit also helps with other aspects of the fabrication process, for example, through an improved form factor of the manufacturing unit as well as overall resource utilization.
Although not widely recognized, on-orbit manufacture of these fibers is now possible due to the revolutionary development over the past decade in the privatization and commercialization of government-owned capabilities supporting a more diverse infrastructure (parabolic, suborbital, orbital); reduced price per pound to orbit; and increased frequency to access space and the microgravity environment. Although hundreds of exotic glasses being considered for applications today would benefit from microgravity REtD and in-space manufacturing, this article focuses on one specific example, the ZBLAN optical fiber. ZBLAN is one of the standards of the terrestrial industry. So far, all the available microgravity data of relevance to exotic optical glasses are based on ZBLAN. It represents the most compelling example on how gravity free manufacturing could solve many of today's problems with exotic glasses. For these reasons, ZBLAN is used in this article to explore the significance of microgravity for advancing commercial exotic glasses and fiber optics technologies. 


\begin{tabular}{|c|c|}
\hline Application Area & Examples \\
\hline Medical & Light guides, imaging tools, and lasers for surgery \\
\hline Defense/government & $\begin{array}{l}\text { IR countermeasures, stand-off detection of explosion } \\
\text { hazards, eye-safe seekers for smart munitions, } \\
\text { covert communications systems }\end{array}$ \\
\hline $\begin{array}{l}\text { Information } \\
\text { technologies }\end{array}$ & Data transmission \\
\hline Fiber lasers & $\begin{array}{l}\text { Plastic and polymer processing, spectroscopy, } \\
\text { noninvasive medical diagnosis, remote sensing }\end{array}$ \\
\hline $\begin{array}{l}\text { Telecommunications } \\
\text { and networking }\end{array}$ & $\begin{array}{l}\text { Connect users and servers in a variety of network } \\
\text { settings and help increase the speed and accuracy } \\
\text { of data transmission. }\end{array}$ \\
\hline $\begin{array}{l}\text { Industrial/ } \\
\text { commercial }\end{array}$ & $\begin{array}{l}\text { Imaging in hard-to-reach areas, (wiring where } \\
\text { electromagnetic interference is an issue); sensory } \\
\text { devices to make temperature, pressure, and other } \\
\text { measurements; nondestructive testing }\end{array}$ \\
\hline
\end{tabular}

$I R$, infrared.

\section{THE VALUE OF EXOTIC OPTICAL FIBERS AND GLASSES: MARKETS AND APPLICATIONS}

The major applications for exotic optical glasses and fibers with selected examples are listed in Table 1 and highlighted in Figure 3. These applications enable several markets of which

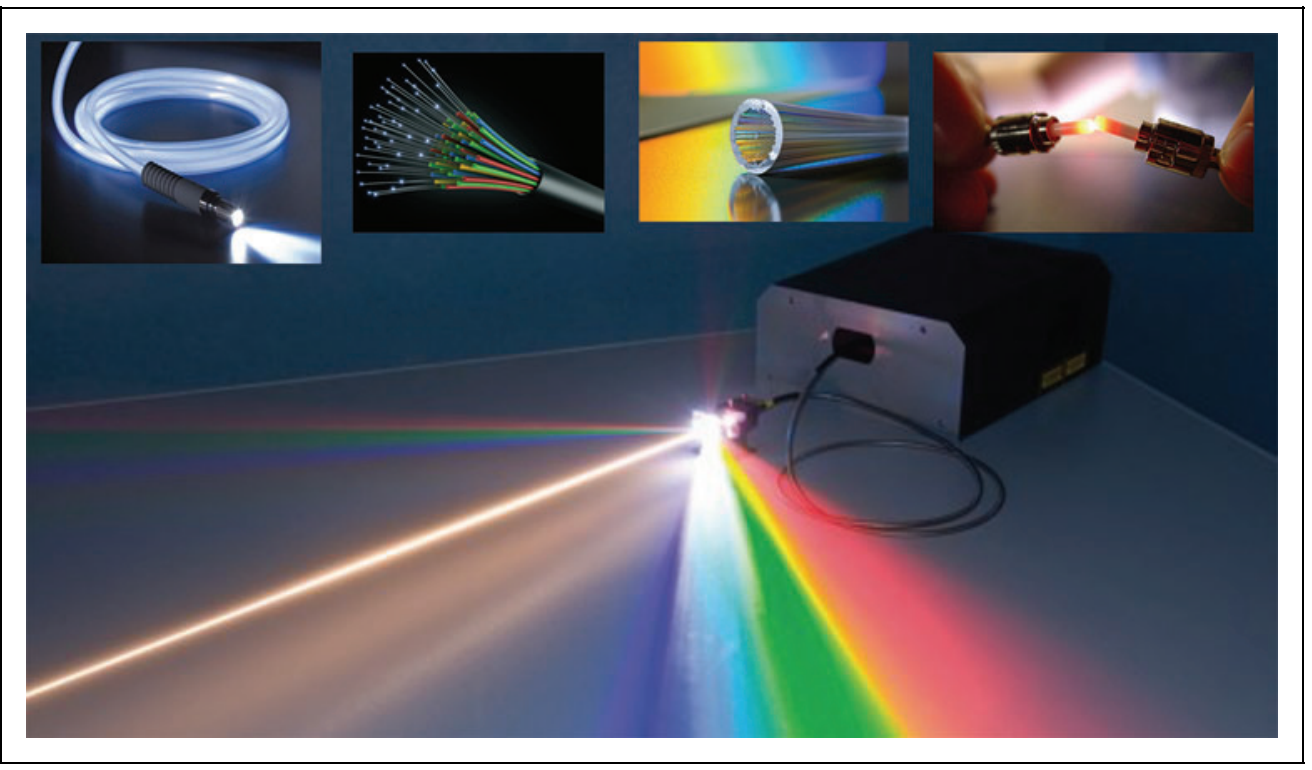

Fig. 3. Technologies relying on exotic optical fibers. Main image: Exotic glass supercontinuum source. Top insets, left to right: ZBLAN optical fiber, hollow core photonic crystal waveguide, fiber optics quantum teleportation motherboard. (Sources: Fiber Optic, Wikipedia, Photonics Society) the total value today is several billion dollars per year. According to a number of industry sources, the overall market for these is growing in 2 ways: (1) The demand for existing applications is increasing, and technology improvements are promoting new applications that open important new markets; (2) the demand for better quality exotic fibers both enables and grows with these markets.

Examples of market analyses that are relevant to exotic optical glasses and fibers are presented next:

1. Future Optical Sensor Market: Exotic optical fibers address critical gaps in the mid-infrared (mid-IR) region for sensors. "The global consumption value of fiber optic point sensors and continuous distributed fiber optics sensor system links during the 2012-2017 timeline will grow at an 'impressive average annual rate of 20.3\%' from $\$ 1.6 \mathrm{bn}$ to $\$ 4.0 \mathrm{bn}$, according to market and technology forecast consultancy ElectroniCast, Aptos, CA, USA."

2. Supercontinuum Sources: Because of its wide bandwidth, ZBLAN and other exotic glasses are of interest as supercontinuum sources. "Quantifying the size of the market for supercontinuum technologies at this point remains a big challenge, but Kaenders <co-founder of Toptica Photonics> estimates it to be worth at least $\$ 50$ millioncomprising approximately $\$ 25$ million for the sources themselves, \$15 million for imaging applications, \$7 million for general laboratory tools, and at least $\$ 3$ million relating to the photonic crystal fiber (PCF) needed to produce the tunable white light, and other accessories."

3. Mid-IR Laser Applications: This is an area where ZBLAN and other exotic fibers play enabling roles. According to Susan Eustis (president, CEO, and co-founder of WinterGreen Research, a high-tech market research firm), "Taking mid-IR QCL <quantum cascade laser $>$ systems to new price to performance levels, vendors bring new capabilities to a broad range of applications. Applications anticipated to gain market traction include: spectroscopic and bio-medical imaging; materials characterization; standoff explosive detection; microscopy; and 
nondestructive testing. Spectroscopy and imaging measurements are now easier, faster and more cost-effective than ever before." Mid-IR sensor markets at $\$ 789$ million in 2012 are anticipated to reach $\$ 7$ billion by 2019 as price performance increases, and unit costs (decreased from $\$ 3,000$ per unit to $\$ 300$ and even to $\$ 8$ or less per unit, on average), drive further interest from commercial buyers. The miniaturization of units from bench-size devices to portable units makes them more useful across the board in every industry.

4. Medical Applications: Mid-IR performance is important to future advances in medicine and dentistry. "In recent years it has become clear that mid-IR imaging spectroscopy has the potential to open a new chapter in bio-medical imaging and offers an effective tool for early cancer diagnosis and improved survival rates. Rather than a search for 'cancer marker' absorption peaks, great progress has been made by analyzing the entire bio-molecular mid-IR spectral signature using automated algorithms. However, the lack of suitable sources, detectors and components has restricted the technology to one of academic interest, based on weak thermal sources, low power lasers or synchrotron research tools. For the first time the photonic technology is in place to develop a new mid-IR technology platform on which entirely novel super continuum sources (c. $1000 \times$ brighter than thermal sources) covering the whole range from 1.5 to $12 \mu \mathrm{m}$.... The potential for revolutionizing the current methods of clinical diagnosis is huge."

5. Defense: Military interest in mid-IR fibers is also rising. "Directed Infrared Countermeasure (DIRCM) systems have the potential to provide effective protection against surface-to-air and air-to-air IR guided missiles by illuminating threats with a high power modulated infrared laser beam. The optical delivery system is one crucial part of a DIRCM system that transports the radiation from the laser source to the turret. Existing DIRCM systems either have the laser co-located with the turret which increases the size and weight of the turret, as well as impacting on through life service, or utilise a complex free-space system, which needs to be customised for each platform fit-out. The development of an optical fibre-based delivery system will allow the laser radiation to be delivered to the turret without requiring continual alignment, and offers a high degree of flexibility in overall system design as well as interoperability between sub-systems and also platforms."
Table 2. ZBLAN Component Heavy Metal Fluoride Powders with Their Characteristic Chemical Formula, Densities, and Melt Temperatures (K) as Well as Their\% Composition in ZBLAN

\begin{tabular}{l|c|c|c|c}
$\begin{array}{l}\text { ZBLAN } \\
\text { Component }\end{array}$ & $\begin{array}{c}\text { Chemical } \\
\text { Formula }\end{array}$ & $\begin{array}{c}\text { Density } \\
\mathbf{g} / \mathbf{c c}\end{array}$ & $\mathrm{T}_{\mathbf{m}} \mathrm{K}$ & $\begin{array}{c}\text { ZBLAN } \\
\text { Composition } \\
\text { Mol (\%) }\end{array}$ \\
\hline Zirconium fluoride & $\mathrm{ZrF}_{4}$ & 4.43 & 1,183 & 53 \\
\hline Barium fluoride & $\mathrm{BaF}_{2}$ & 4.89 & 1,641 & 20 \\
\hline Lanthanum fluoride & $\mathrm{LaF}_{3}$ & 5.94 & 1,766 & 5 \\
\hline Aluminum fluoride & $\mathrm{AlF}_{3}$ & 2.88 & 1,564 & 4 \\
\hline Sodium fluoride & $\mathrm{NaF}$ & 2.56 & 1,266 & 20 \\
\hline
\end{tabular}

In a gravitational environment, the quality and stability of the final glass is impacted by sedimentation, heterogeneous crystallization, and vitrification, creating a wide variety of defects (bubbles, crystals, inclusions, regions with over-densification, etc.) that lead to light scatter and high attenuation.

\section{EXOTIC OPTICAL FIBERS AND GLASSES: DEFINITIONS AND PROPERTIES}

Fiber optics represents a communication environment through which optical signals are sent down micron diameter strands of extremely pure glass or fiber. The light is guided down the center of the fiber called the "core." The cladding surrounding the core is an optical material with a high index of refraction that ensures that light remains trapped inside the core. To protect the fiber from moisture and other mechanical damage, the fiber itself is coated by a buffer, which is then striped off the fiber for termination or splicing. Both core and cladding are usually made of ultra-pure glass. Exotic glasses are made from a complex formulation of materials, including metal fluorides and rare earth elements, which can be melted together in a wide range of combinations and drawn into optical fibers for different applications (Table 2).

The "parent" fluorozirconate powders underlying the fluoride glass families are $\mathrm{ZrF}_{4}$ and $\mathrm{HfF}_{4}$; to these, other fluoride glasses such as $\mathrm{AlF}_{3}, \mathrm{GaF}_{3}, \mathrm{InF}_{3}$, etc are added as main glass formers. The ultimate properties (glass stability, durability in ambient air and humidity, mechanical strength, low optical loss, phonon energy, chemical durability, etc.) of the resulting glasses as well as their time and temperature stability differ significantly.

Heavy metal fluoride glasses were first discovered accidentally by Poulain et al. in 1975. The initial composition was a mix of $\mathrm{ZrF}_{4}-\mathrm{BaF}_{2}-\mathrm{NaF}$. The resulting glass was not stable enough and required addition of other metal fluorides to help with vitrification and to increase stability against crystallization. The addition of small percentages of $\mathrm{AlF}_{3}$ and $\mathrm{NaF}$ 


\begin{tabular}{|c|c|}
\hline Main Glass Constituents & Composition (mol\%) \\
\hline ZBLAN & $53 \mathrm{ZrF}_{4} 20 \mathrm{BaF}_{2} 5 \mathrm{LaF}_{3} 4 \mathrm{AlF}_{3} 20 \mathrm{NaF}$ \\
\hline HBLA & $57 \mathrm{HfF}_{4} 34 \mathrm{BaF}_{2} 5 \mathrm{LaF}_{3} 4 \mathrm{AlF}_{3}$ \\
\hline YABC & $20 \mathrm{YF}_{3} 20 \mathrm{BaF}_{2} 40 \mathrm{AlF}_{3} 20 \mathrm{CaF}_{2}$ \\
\hline IZBS & $40 \mathrm{InF}_{3} 20 \mathrm{ZnF}_{2} 20 \mathrm{SrF}_{2} 15 \mathrm{BaF}_{2} 5 \mathrm{CaF}_{2}$ \\
\hline
\end{tabular}

Additional tuning of their properties for a particular application can be achieved through doping with rare earth elements.

helped in stabilizing the resulting glass, $\mathrm{ZBLAN}, \mathrm{ZrF}_{4}-\mathrm{BaF}_{2}-$ $\mathrm{LaF}_{3}-\mathrm{AlF}_{3}-\mathrm{NaF}$, the composition that is the most often used for bulk and fiber optics applications (Table 3).

Heavy fluoride glasses can be combined for particular transmission characteristics; they are also doped with a wide range of rare earth elements $\left(\mathrm{Nd}^{3+}, \mathrm{Yb}^{3+}, \mathrm{Er}^{3+}, \mathrm{Tm}^{3+}, \mathrm{Pr}^{3+}\right.$, $\mathrm{Dy}^{3+}, \mathrm{Ho}^{3+}$ ) to enable an even wider range of specific and important military and medical applications (Fig. 4). The current most important rare-earth-doped fibers are erbiumdoped fibers for fiber amplifiers and ytterbium-doped fibers for high-power fiber lasers and amplifiers. Some fibers are intentionally doped with 2 different kinds of rare earth ions (co-doping). The most popular is the combination of erbium and ytterbium (Fig. 5). To extract maximum benefit from the rare-earth-doping process of fluoride fibers, it is even more important for the base fiber to be homogeneous, have minimum background loss, be chemically able to host a convenient amount of active ions, and withstand high-energy pumping.

There are 2 major categories of fibers: single mode and multi-mode (Fig. 6). In fiber-optic communication, a single-

\begin{tabular}{l|c|c}
\multicolumn{2}{l}{ Table 4. Major Manufacturers of Exotic Fibers } \\
ZBLAN Fiber Type & Manufacturer & Website \\
\hline ThorLabs & US & www.thorlabs.us \\
\hline IR-Photonics & Canada & www.irphotonics.com \\
\hline FiberLabs, Inc. & Japan & www.fiberlabs-inc.com \\
\hline Le Verre Fluore & France & www.leverrefluore.com \\
\hline Idil Fibre Optiques & France & www.idil.fr \\
\hline YSL Photonics & China & www.yslphotonics.com \\
\hline
\end{tabular}

mode optical fiber is an optical fiber that is designed to carry only a single ray of light (it supports 2 modes that are orthogonally polarized). Because of this, the number of light reflections created as the light passes through the core decreases, lowering attenuation and creating the ability for the signal to travel faster and further. Multi-mode optical fibers, however, are mostly used for signal transmission over short distances. Other classes can be defined based on the composition of the core and core/cladding diameters (usually expressed in microns):

- Single-Mode Fluoride Fiber (SMFF): These fibers provide stable high bandwidth light transmission over long distances (telecommunication, TV services). They also represent an accurate optical guide for IR spectroscopy, especially due to very good absorption bands for the strong vibrations of $\mathrm{C}-\mathrm{H}$ and $\mathrm{N}-\mathrm{H}$ at 3 microns.

- Multi-Mode Fluoride Fiber (MMFF): These fibers provide stable optical transmission over short distances and carry concurrently multiple rays of light (modes), each at a slightly different reflection angle within the optical fiber core. These modes, however, tend to disperse over longer lengths.

- Double Cladding Fluoride Fiber (DCFF): ZBLAN-DCFF (Double Cladding Fluoride Fiber) is used for high-power fiber lasers and amplifiers with unique wavelengths. This fiber provides superior pump absorption efficiency and easy fiber handling.

- Polarization-Maintaining Fibers (PMF): Used in fiber lasers, single-polarization fibers guarantee polarized laser emission. There are also various uses in the field of fiberoptic sensors where polarization mode dispersion effects limit the ultimate bandwidth and can be addressed through deliberately introducing birefringence (elliptical core fibers) or designing single-polarization single-mode fibers.

- Rare Earth-Doped Fibers: These fibers provide highefficiency emissions and are used for fiber lasers, optical amplifiers, etc. in a wide range of applications. They could be single mode, multi-mode, double clad, d-shaped, or ring core.

A list of major terrestrial manufacturers of exotic fibers is compiled in Table 4.

\section{Key Properties of Exotic Optical fibers}

An optical fiber works based on the principle of total internal reflection determined by the difference in the indices of refraction between the core and the cladding material. 


\section{COZMUTA AND RASKY}

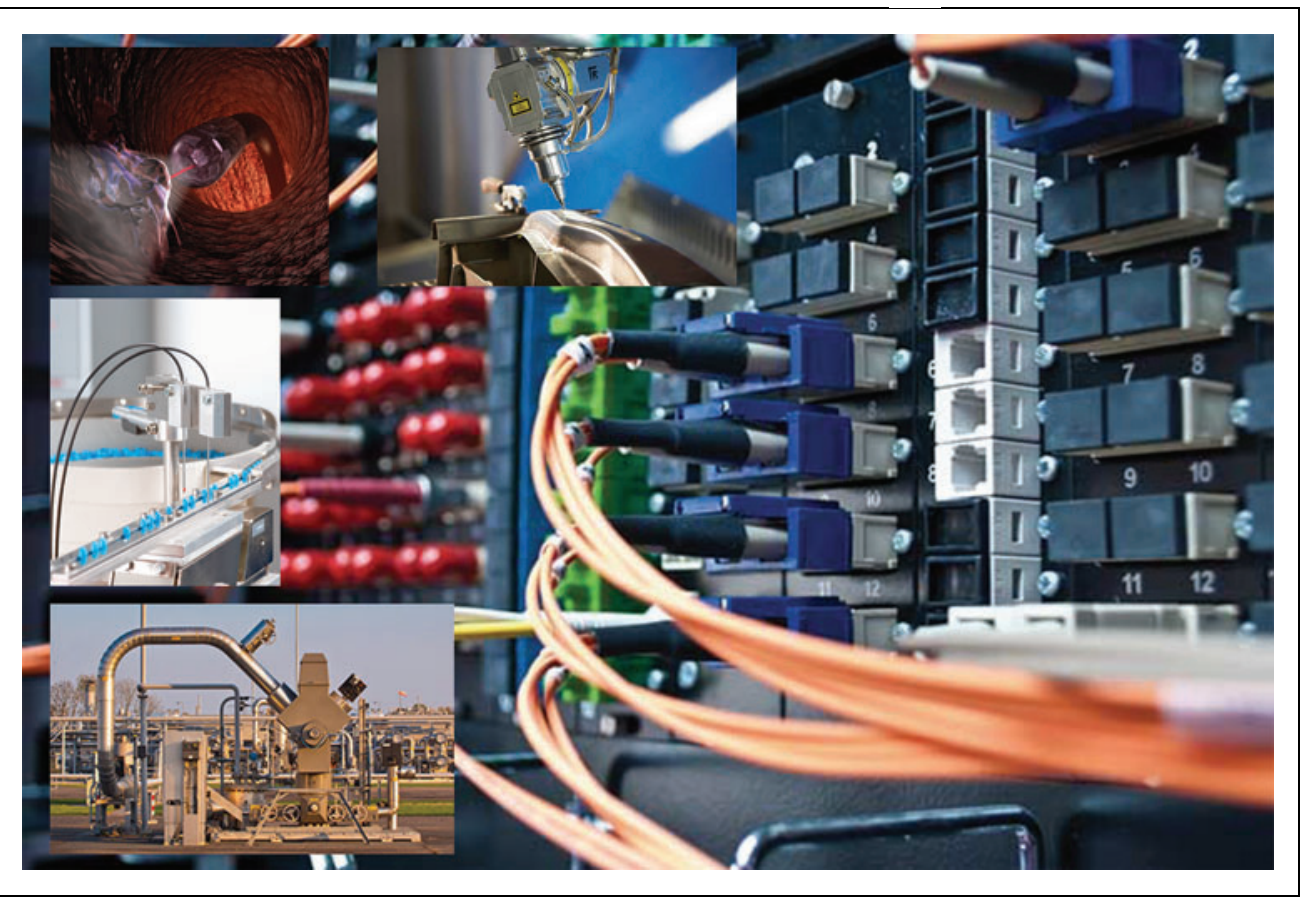

Fig. 4. Major applications for exotic optical fibers technologies. Main image: Information and communication technology. Insets (top to bottom, left to right): medical applications, sensor applications, downhole sensing for oil and gas applications, manufacturing applications. (Sources: Optics Photonics News, Sensopart, Photonics Society, Fiber Optics)

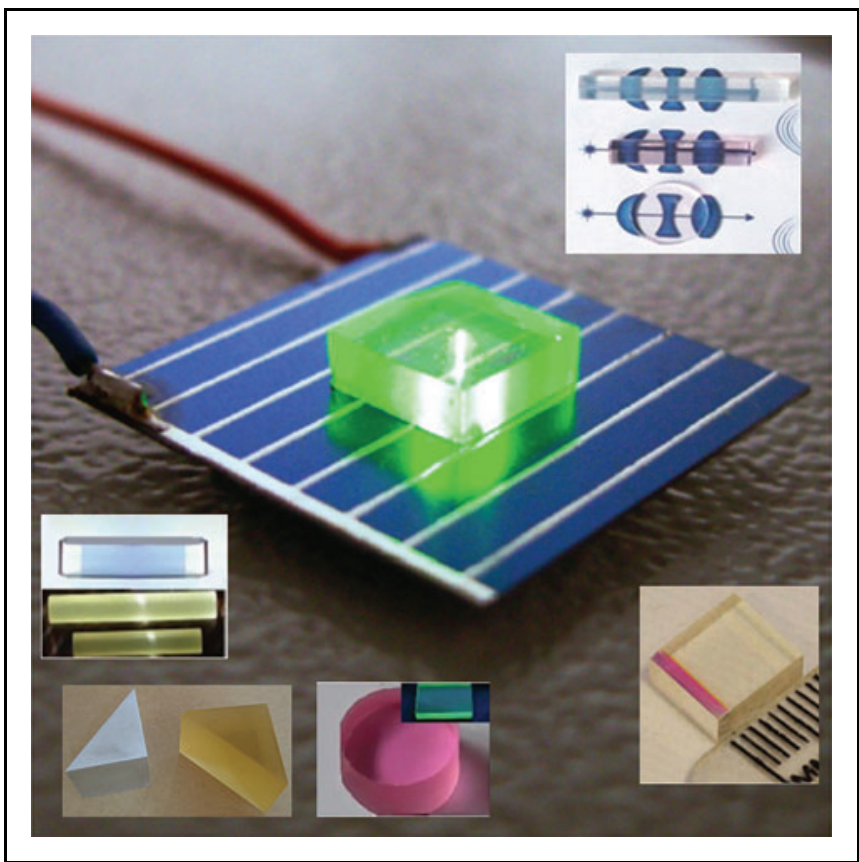

Fig. 5. ZBLAN glasses and preforms. Main image: ZBLAN doped glass charging on a solar cell. Insets: ZBLAN lenses (top right); ZBLAN preforms with and without doping (bottom left); ZBAN chip (bottom right). (Sources: Photonics Society, Wikipedia, SPIE)
Attenuation as a function of incident light wavelength is the key indicator of a fiber's performance. As described earlier, a fiber's ability to transmit in specific wavelengths is what enables specific applications. Figure 7 compares attenuation properties of silica, ZBLAN, $\mathrm{ZnF}_{2}$, and $\mathrm{InF}_{2}$ optical fibers. This comparison is generic and its purpose is to highlight the wide range of variation in the properties of such fibers, especially with reference to a theoretically estimated "absolute" performance that could be potentially achieved for ZBLAN in a gravity-free environment.

Raw materials needed in the fabrication of silica fibers are more readily available. It is also much less expensive to produce silica fibers (sales prices are as low as $\$ 20 / \mathrm{m})$. By comparison, ZBLAN commercial prices are $\$ 150 / \mathrm{m}$ to $\$ 300 / \mathrm{m}$, depending on quality and composition. Custom exotic fibers are typically sold from $\$ 300 / \mathrm{m}$ to $\$ 3,000 / \mathrm{m}$. These are the main reason behind the current widespread use of silica fibers, especially for communication-related applications. In addition, silica fibers are also stronger and more flexible than ZBLAN. Multiple kilometer lengths of silica fiber can be manufactured in a single run, which is a significant advantage for longdistance telecommunications. In contrast, although kilometer lengths are possible and 700-m lengths of ZBLAN are commercially produced, costs constrain the demand for longer lengths of ZBLAN fibers. Other exotic glasses can only be produced in significantly shorter lengths. In theory, a

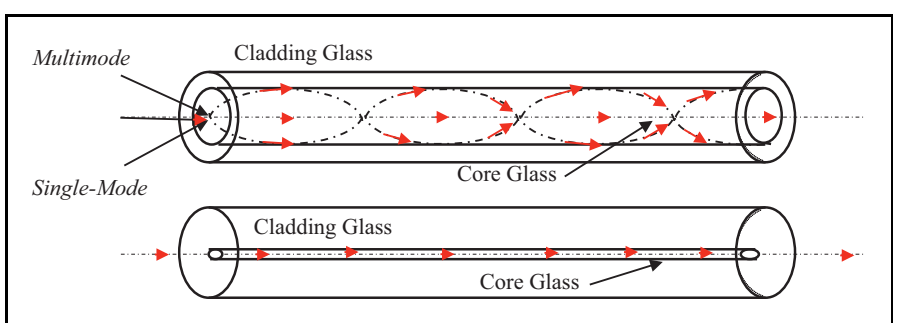

Fig. 6. Schematic representation of single and multi-mode fiber optics. (Sources: Fast Science) 


\section{TERRESTRIAL MARKETS AND MATERIAL PROCESSING IN EARTH'S ORBIT}

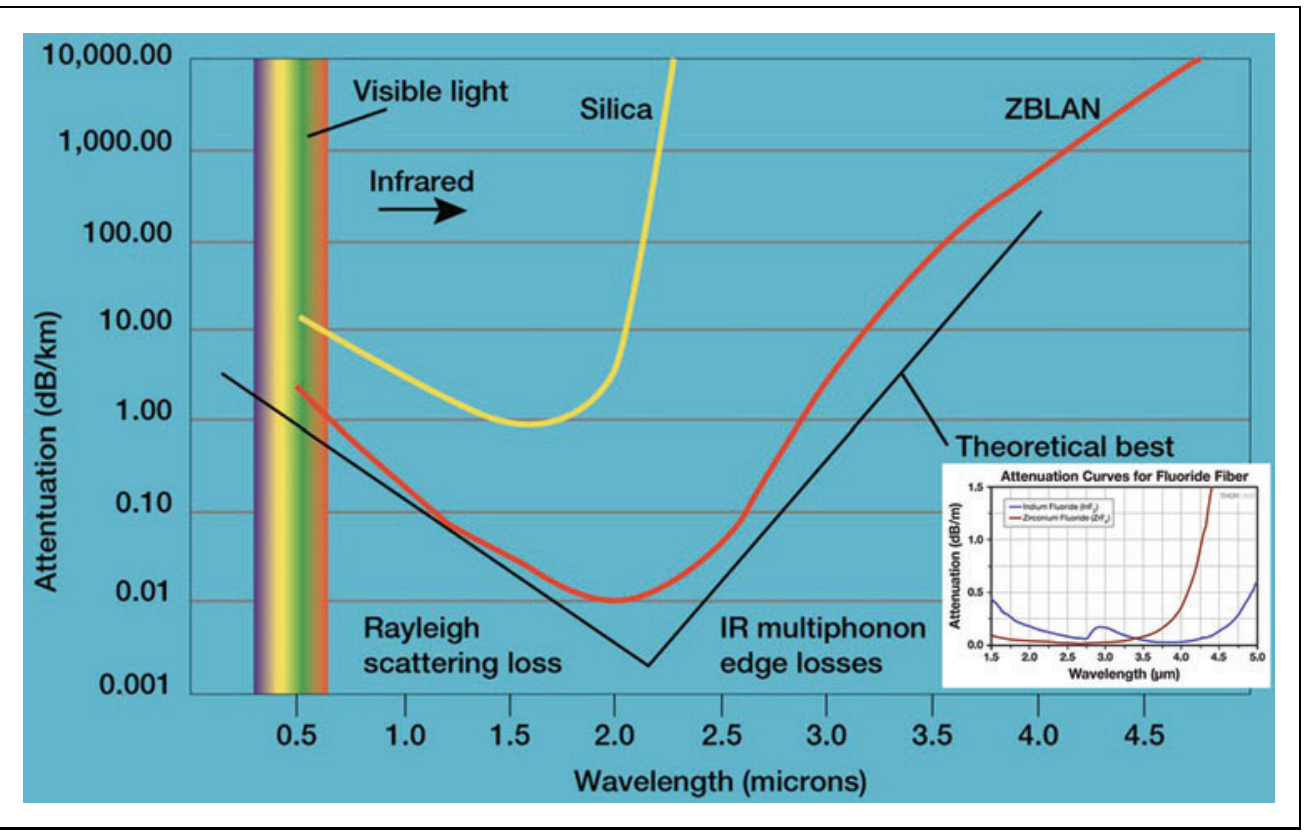

Fig. 7. Generic comparison of attenuation (dB/unit length) properties as a function of incident light wavelength (microns) for silica, $\mathrm{ZBLAN}, \mathrm{ZnF}_{2}$, and $\mathrm{InF}_{2}$ fibers. Attenuation is a direct measure of how much intensity is lost as a light beam or signal travels through a transmission medium, that is, an optical fiber. The lower the attenuation for the wavelengths of interest, the higher the quality of the transmission output. Comparison of attenuation $(\mathrm{dB} / \mathrm{km})$ properties as a function of wavelength (microns) for gravity-manufactured ZBLAN (red line) versus silica fibers (yellow line). A "perfect" ZBLAN fiber could carry light with attenuation near the theoretical best allowed by matter, calculated by using the classical scattering theory. The fabrication of such "perfect fibers" in a gravity environment is nearly impossible due to fast crystallization rates which also need to be optimized for optimized surface area to volume ratios. Of importance to attenuation measurements is the sample geometry, that is, sufficient lengths of fibers need to be produced to avoid property extrapolation over small fragments to longer lengths. Inset: Attenuation $(\mathrm{dB} / \mathrm{m})$ as a function of wavelength values for ZBLAN and Indium Fluoride fibers manufactured by ThorLabs. (Source: Wikipedia, ThorLabs)

kilogram of preform can produce $3 \mathrm{~km}$ of fiber. In practice, that has not been achieved for exotic fibers, so all of today's applications of exotic fibers use much smaller lengths.

However, despite its ease of manufacture and low cost, there are significant limitations to silica-based fibers. Compared with ZBLAN, silica transmission losses are very high, their transmission quality is poor, and the bandwidth available for signal transmission is very narrow. This is especially true in the mid-IR region where silica transmission cuts off at about $2 \mu \mathrm{m}$ (Fig. 7). There are many industrial, military, computer, and medical applications that require fibers and glasses in this range, and these are discussed in more detail in the Introduction. Further, as the demand for higher bandwidth communications increases exponentially worldwide, the demand for fibers that overcome the limitations of silica is increasing proportionally. Exotic fibers have been identified by the industry as one of the potential components that can help meet this demand.

\section{THE PROCESS \\ OF TERRESTRIAL PRODUCTION AND ITS GRAVITY LIMITATIONS}

The ideal fiber would combine the wide bandwidth and low transmission losses of ZBLAN with the fiber lengths, ease of manufacturing, and robustness of silica. Fabrication from melted glass rather than from the more pristine technique of vapor deposition used to form silica-based fibers creates inherent problems for exotic optical fibers (formation of bubbles, density irregularities, core-clad interface irregularities, small preform sizes limited by crystallization rates, vitrification, and environmental contamination), limiting attenuation and other critical optical properties.

Fabrication of exotic glasses can be described in 2 main steps:

1. Melting of the preform (Fig. 8): A selection of heavy metal fluoride powders is melted together to create a blank or preform.

2. Pulling of the optical fiber (Fig. 9): A vertical unit is required to produce fibers by melting the end of the preform and drawing the fibers onto a take-up spool.

The first gravity-driven influence occurs in the ZBLAN preform fabrication (Fig. 8) process where sedimentation due to the different densities of the compound powders and their different characteristic melting temperatures impact the structure and property of the viscous melt (Table 2). Many of these compound powders are immiscible in the melt. In addition, the rate at which each component in the mix reaches its melting temperature is also sensitive to gravity-induced convection. All these factors lead to nonuniform melting spots during the process of preform fabrication.

Once formed, the ZBLAN preform is characterized by 3 temperatures: the melt temperature, $T_{m} \sim 723 \mathrm{~K}$; the crystallization temperature, $T_{c} \sim 620 \mathrm{~K}$; and the glass transition temperature, $\mathrm{T}_{\mathrm{g}} \sim 530 \mathrm{~K}$. The smaller the interval $\left(\mathrm{T}_{\mathrm{c}}-\mathrm{T}_{\mathrm{g}}\right)$, the more difficult the 


\begin{tabular}{|c|c|c|c|c|}
\hline & $\begin{array}{l}\text { HEAVY METAI } \\
\text { POWDER MIX }\end{array}$ & $\begin{array}{l}\text { ORIDE } \\
\text { MELTING }\end{array}$ & PREFORM & OPTICAL FIBER \\
\hline $\begin{array}{l}\text { CORE } \\
\text { CLADDING }\end{array}$ & & & & \\
\hline
\end{tabular}

Fig. 8. Fiber optics production starts from a mix of heavy metal fluoride powders (Table 2) mixed together and subjected to melting (Table 2) into a preform. The preform is then pulled into an optical fiber. (Sources: Wikipedia, Photonics Society)

fiber drawing process due to the occurrence of crystallization effects. For ZBLAN this difference is $\sim 100 \mathrm{~K}$ and, thus, care must be taken during fiber drawing to avoid crystallization.

ZBLAN is very sensitive to water and other environmental constituents, requiring fabrication to take place in a wellcontrolled environment (very dry and clean atmosphere). This is true regardless of whether manufacturing occurs in space or on Earth.

Another important aspect that is specific to terrestrial manufacturing is the need for the fiber puller unit to be vertical (Fig. 10): On the one hand, gravity helps with the initial capturing and pulling of the melted preform into the optical fiber; on the other hand, it also severely restricts the length of

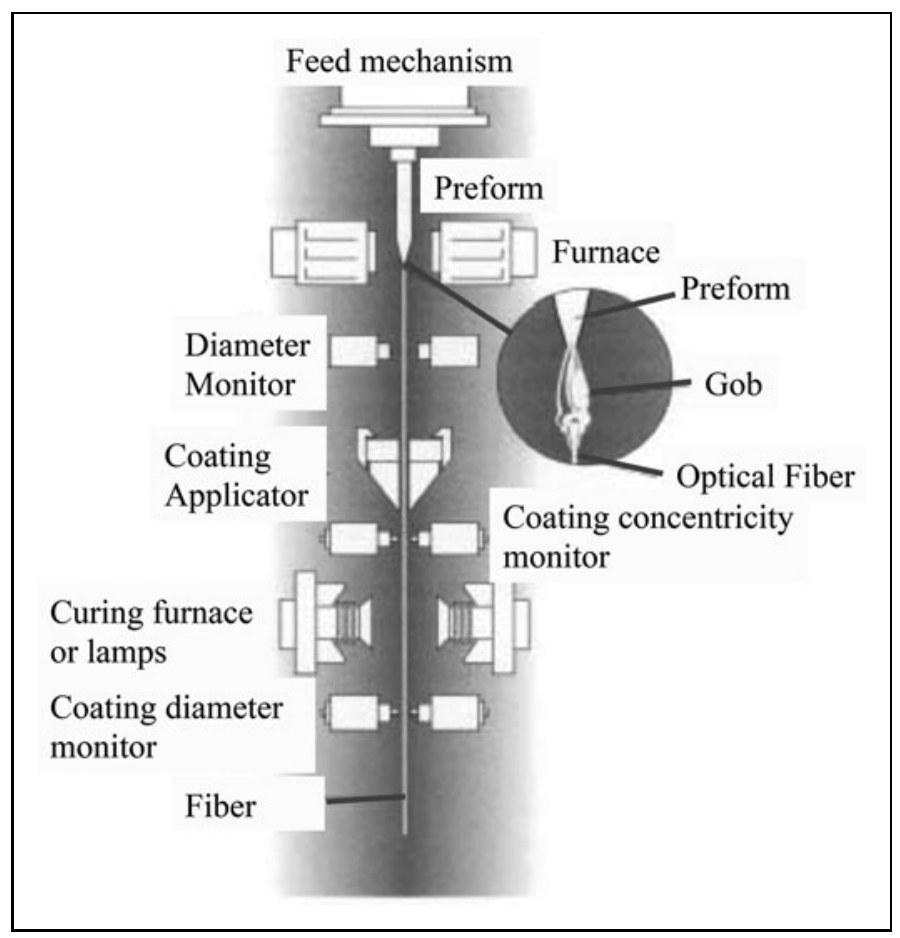

Fig. 9. Schematic representation of the fabrication process of exotic fibers through direct melt. monolithic exotic optical fibers that can be pulled. For example, 700-m length ZBLAN and Indium Fluoride fibers have been successfully pulled but such lengths are actually quite uncommon. In contrast, silica fibers are routinely pulled to lengths of multiple kilometers. To generate kilometer-long exotic optical fibers, the ends of the optical fibers must be carefully cleaved, fused, and finally mechanically spliced together with their cores perfectly aligned. Special optical fiber connectors for temporary or semi-permanent connections may also be used. Over time, however, mechanical and transmission problems usually develop at the splice. Longer lengths of optical fibers enable communication over long distances with fewer dropouts or transmission problems and require less infrastructure (signal amplifier) in place to ensure operational stability.

The limitations listed earlier diminish the yield, transmission quality, strength, and value of a fiber; constrain the range of applications that can be developed from it; and are characteristic to the entire class of exotic glasses and fibers. Wavelengths, bandwidth, transmission quality, length and robustness of fibers, and ease of manufacturing define both the price and the specific applications that are enabled by an optical fiber.

\section{MICROGRAVITY IN EARTH'S ORBIT: A NEW ERA OF COMMERCIAL CAPABILITIES}

There are 4 major categories in which the value of longterm exposure to the microgravity environment can be extracted:

1. New insights into systems behavior and response to variations in their environment and identifying new final states of systems. This knowledge is captured in LEO through a series of targeted experiments. A technology is then developed on ground that is able to mimic the newly observed state of the system. The technology is then commercialized. Examples include bulk metallic glasses and microencapsulation for cancer diagnostics and treatment.

2. Processing/reprocessing in space of products manufactured on Earth. This approach seeks improvements in the ultimate properties and performance of the product by having it undergo a processing cycle in space. Examples include exotic optical fibers and compound semiconductor wafers. 


\section{TERRESTRIAL MARKETS AND MATERIAL PROCESSING IN EARTH'S ORBIT}

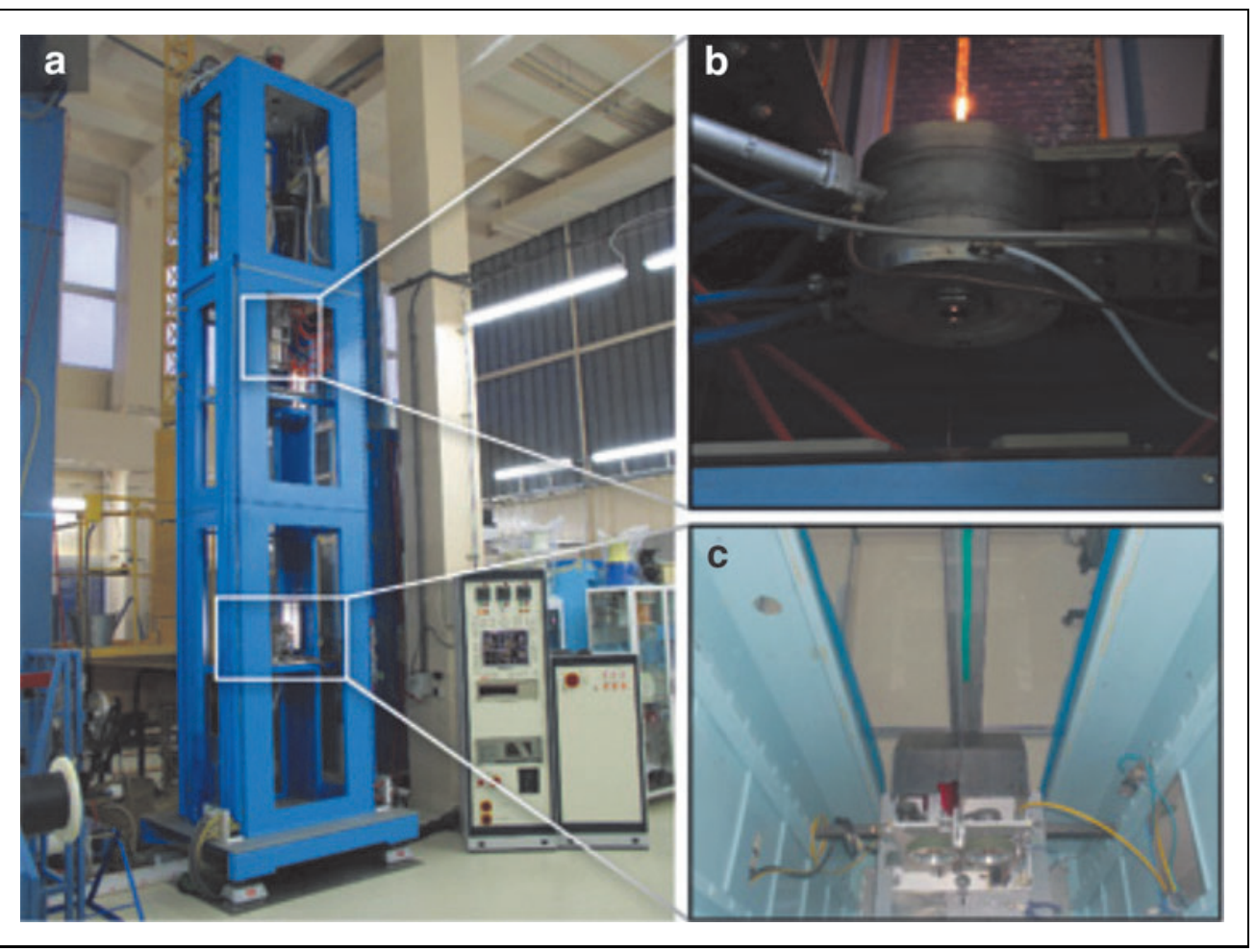

Fig. 10. A typical fiber drawing tower (a) including a high-temperature furnace for glass melting (b) and various fiber fabrication units (c). (Sources: Laser Focus World, SPiE)

3. Manufacturing and assembly in space. This is the process in which a product is built in the reduced gravity environment, usually from its component elements. Although existing examples in this arena are scarce (space beads), future success stories can be developed from promising candidates. Exotic optical fibers are possibly the most promising candidates for in-space manufacturing.

There is an additional benefit emerging from the development of space technologies. Through the need to develop or mature a technology for operation and use in space, that technology turns out to be of serendipitous value on Earth. This aspect will, however, not be discussed in this article.

In the past decade, there was a paradigm shift in terms of the privatization of government-owned capabilities supporting infrastructure (parabolic, suborbital, orbital) access to space (Fig. 11). This has spurred a whole New Space Economy that, so far, has emerged primarily around satellite delivery and operation, remote sensing, imaging from space, and cubesats/nanosats since these market verticals provided the most attractive shortterm business opportunities. Microgravity discoveries are still limited to the first category listed earlier (New Insights), although a great opening to reprocessing as well as manufacturing in space emerges.
Commercial research in space works very similar to commercial research on ground: Frequent iteration is required to identify the best formulation that meets desired product specifications. This paradigm translates into 3 requirements for the flight infrastructure: (1) competitive price point, (2) reliability and repeatability, and (3) easy access and versatility.

The cost of space transportation has always been very high and has, in general, been viewed as one of the biggest obstacles to space commercialization. However, it has historically been difficult to objectively evaluate the true space transportation cost since most launch vendors do not publish standardized cost breakdown numbers. The costs of launch vehicles are usually compared by computing the cost to place 1 unit mass (pound or kilogram) of payload into a specific orbit (frequently LEO or GEO).

On average, launch costs per kilogram to LE0 are about $\$ 5,000$ USD ( $\sim \$ 11,000$ USD per pound), though some countries subsidize space launches, which can reduce end costs. The United Launch Alliance (ULA) quotes an average mission price of \$225M for all Atlas and Delta launch services (for a performance ranging between $10,000 \mathrm{~kg}$ for Atlas V 401 and 28,370 kg for Delta IV Heavy). SpaceX currently sells off-the-shelf Falcon 9 launches for $\$ 61.2 \mathrm{M}^{*}$ for a total performance of $13,150 \mathrm{~kg} .^{\dagger}$ Elon Musk, owner and CEO of SpaceX, indicated at the National Press Club that the cost of propellants is only $0.3 \%$ the cost of a rocket (this yields about $\$ 200,000$ for a $\$ 60$ million launch) and that the first stage cost is approximately "less than three-quarters" of the cost of the entire rocket. If full reusability of Falcon 9 (both first and second stage) could be achieved, the total price of the launch would go down about 1 order of magnitude. Although full reusability is very difficult to achieve (although not impossible), even with partial reusability prices would go down and the quantity produced would go up through economies of scale. The

*Prices quoted on the SpaceX website: www.spacex.com/about/capabilities (last accessed Aug 28, 2017)

The effective Dragon payload is $6,000 \mathrm{~kg}$ upmass and $3,000 \mathrm{~kg}$ downmass, www.spacex.com/dragon (last accessed Aug 28, 2017) 


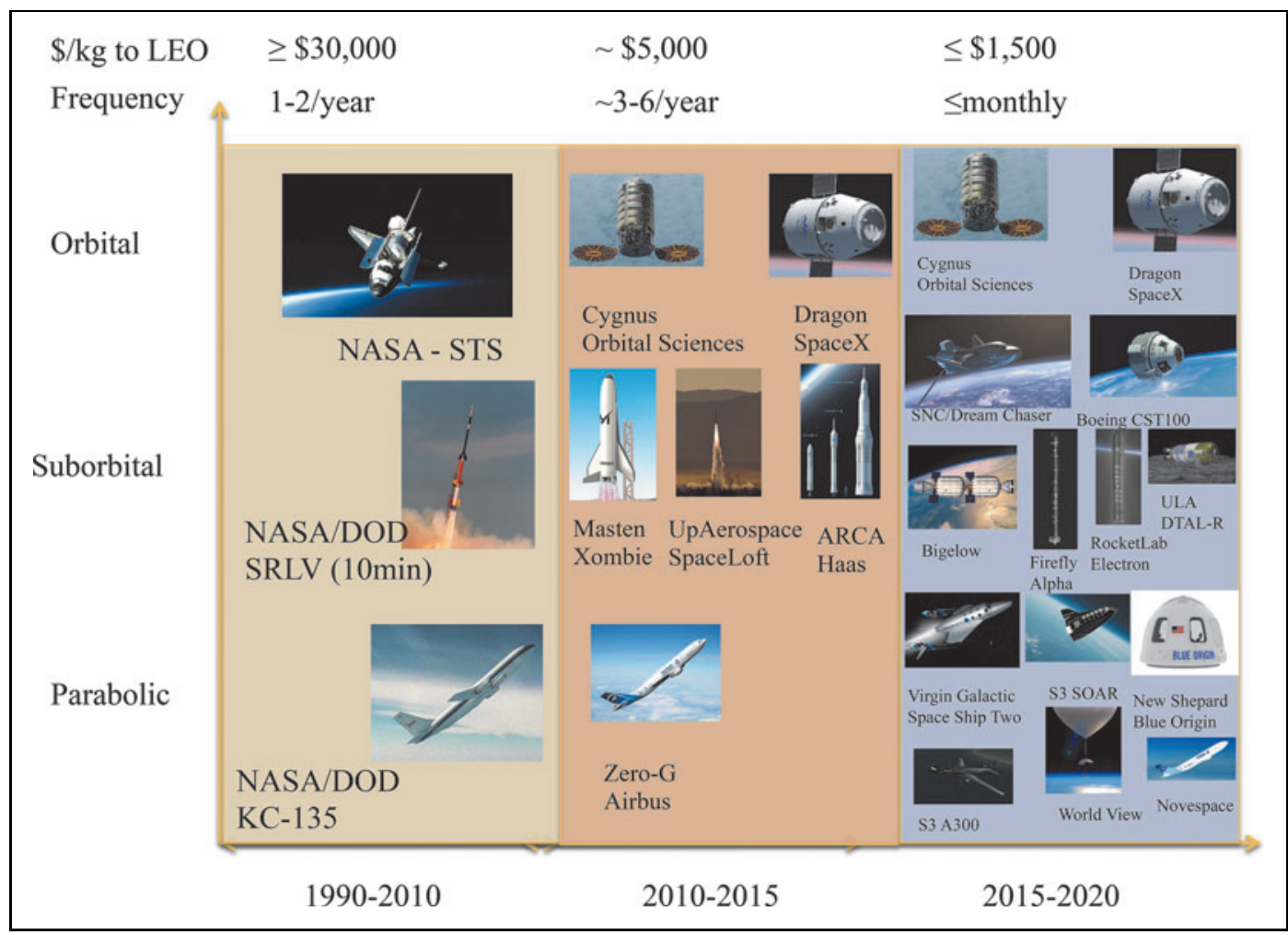

Fig. 11. A major limitation to date in taking full advantage of the microgravity and space environment has been the extremely high price of launch costs (usually referenced as \$/kg to Low Earth Orbit [LEO]). The microgravity environment is accessible for various durations through parabolic ( $\sim 20 \mathrm{~s})$, suborbital (3$5 \mathrm{~min}$ ), and orbital (days, months, years) flights. Over the past 2 decades, the commercialization and diversification of space infrastructure has resulted in a significant increase of flight frequency as well as lowering of the price per pound to orbit.

recent successes of return to launch point (the first step toward reusability) of Blue Origin's Sheppard vehicle (suborbital) and SpaceX's Falcon 9 first stage (orbital) are historical turning points that have the potential to open up truly innovative global opportunities.

In terms of robustness and reliability, the SpaceX rocket is quoted at $\sim 5 \%$ failure rate and the ULA rocket is quoted at $<1 \%$ failure rate. These numbers would be expected to fall as launch frequency increases.

Total private dollar investments in space have also been on the rise, with 1995-2002 annual totals (except 1998) being around \$2.5 million and with a significant increase toward the $\$ 2.5$ billion in 2015 (Fig. 12).

These recent successes also offer new opportunities for affordable commercial microgravity research, which, in turn, helps fuel new markets. A growing number of companies (Nanoracks, Techshot, Blue Origin, Bioserve, Space Tango, Zin Technologies, XCor, FOMS Inc, POC, ACME advanced materials, Made in Space, etc.) are now offering a wide variety spectrum of support for microgravity research; providing quick, versatile, and costcompetitive experiment development and ISS integration services for new users of space, ranging from academic to industry RED.

\section{FROM FIBER \\ DRAWING \\ TO ON-ORBIT MANUFACTURING: PAST, PRESENT, AND FUTURE}

Gravity-induced convection and sedimentation are almost absent in the microgravity of low Earth orbital space. This allows more homogenous distributions of different materials to be maintained in mixtures, and it prevents unwanted crystallization by reducing convection-driven cooling. Numerous experiments in microgravity on the Space Shuttle and on the International Space Station have enabled these findings.

In the mid-1990s, ZBLAN was a promising material that could not be manufactured well enough on Earth to open a commercial market. Dr. Dennis Tucker of the Marshall Space Flight Center hypothesized that the manufacturing of ZBLAN preforms in microgravity might prevent unwanted crystallization.

Tucker produced ZBLAN preforms during 20s of microgravity on a parabolic aircraft by using the same flight unit. By comparing ZBLAN fibers pulled in microgravity and in $1 \mathrm{~g}$, he concluded that crystallization did not occur in microgravity and the resulting optical fibers manufactured in microgravity were significantly superior to the 1-g fabricated fibers (Fig. 13).

In comparison, it took an additional decade of research on Earth to achieve the same result for ZBLAN through terrestrial manufacturing and it is, in fact, very possible that the early experiments on parabolic flights in microgravity are partly responsible for these advances, especially since this success has not been replicated to the same degree for almost any of the other exotic fibers.

The next natural step to Dr. Tucker and his team at that time was to prepare a Space Shuttle investigation to access longer 


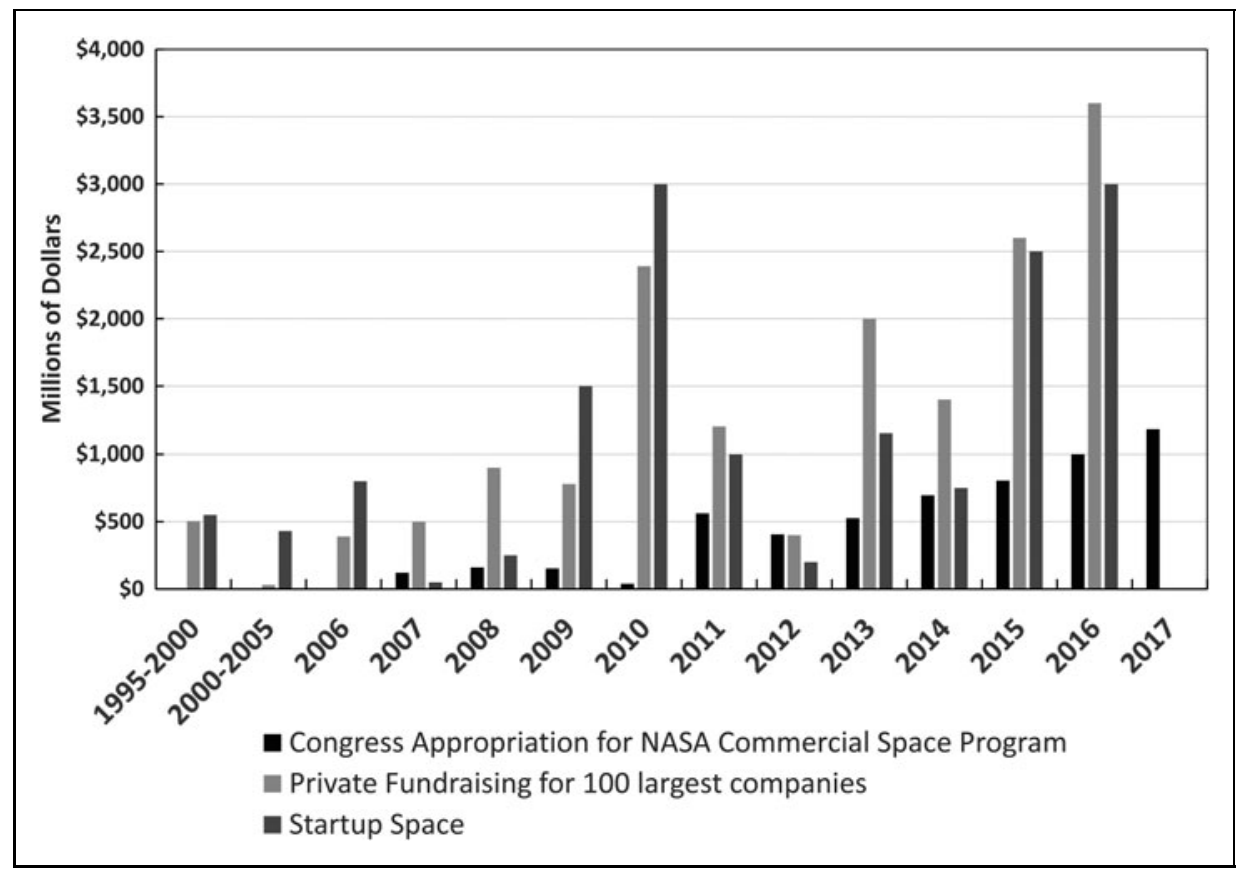

Fig. 12. Private investments in space, as highlighted by a wealth of recent market and economic reports adapted from Goldman Sachs, ${ }^{4}$ Organisation for Economic Co-operation and Development (OECD), ${ }^{5}$ Robert Zimmerman, ${ }^{6}$ various public Law documents, Consolidated and Further Continuing Appropriations Act, and the NASA budget, have increased significantly over the past 2 decades.

durations of microgravity exposure. However, the Space Shuttle was needed to build the International Space Station and many flight R\&D programs were cancelled, with Space Shuttle flights being focused on the ISS. The space R\&D for ZBLAN was put on hold. To date, ZBLAN has not been fabricated in low Earth orbit.

In early 2011, the Air Force sought to fabricate low-loss ZBLAN fibers with wide spectral band optical transmission for satellite tracking systems enabling the expansion of the detection range from the ultraviolet to the mid-IR wavelengths. Interest in microgravity for ZBLAN production resumed. Dr. Dmitry Starodubov, of Fiber Optics Manufacturing in Space, FOMS, Inc. (at that time affiliated with Physical Optics Corporation), was awarded a Phase II SBIR research grant. This resulted in an updated demonstration on a parabolic aircraft flight in 2012 (Fig. 14) followed by a ZBLAN fiber drawing experiment in low gravity on a Black Brandt V sounding rocket.

As discussed earlier, ZBLAN manufacture has 2 major steps: production of the preform and pulling the fibers. Tucker's group had investigated the role of microgravity in producing a ZBLAN preform and demonstrated that microgravity made a critical difference in producing glass free of crystallization. Dr. Starodubov took the next step, that is, producing ZBLAN fibers in microgravity by melting the preform and pulling it from a rod
$10-15 \mathrm{~mm}$ in diameter into a glass fiber $\sim 125$ microns in diameter, that is, a 1,000-fold reduction in size (Fig. 15).

The conclusion after repeating the experiment on the sounding rocket was that the landing forces were too extreme to recover enough of the fragile glass product to be of value and research turned back to the parabolic capability (Zero-G). In this process, a human-rated, triple-contained zero-g fiber pulling unit was developed. ZBLAN fibers were pulled from a standard quality ZBLAN preform. No attempt was made to optimize the preform quality by using one of the higher priced sources of ZBLAN. The findings highlighted, again through both visual and scanning electron microscope inspection, that ZBLAN fibers made in 20s of microgravity have significantly superior properties to the ZBLAN fibers made in the same apparatus in $1 \mathrm{~g}$.

During the 20 years since the original ZBLAN microgravity research, the state of the art of manufacturing fluoride fibers on the ground improved considerably, driven by market demand. For comparison, Figure 15C shows the best ZBLAN fibers produced on Earth (courtesy of ThorLabs). The ZBLAN produced on Earth by ThorLabs is of a higher quality because it was also made from the highest quality preform under optimal laboratory conditions. In contrast, the microgravity-produced fibers were manufactured in 20s by using an inferior grade of ZBLAN in a parabolic aircraft where there was a 1.8 -g acceleration on both the ascent and descent phases.

Finally, the improved quality of the microgravity-produced ZBLAN over the 1-g control was achieved after only 3 parabolic flights. The highest quality terrestrial ZBLAN took $>2$ decades of research on Earth to achieve. Nevertheless, the magnitude of improvement seen between the flight and ground ZBLAN fibers and preform that used the average quality ZBLAN preforms is impressive. In fact, FOMS Inc holds a Trademark on Space Fiber ${ }^{\mathrm{TM}}$ The Space Portal/Emerging Space Office has been at the epicenter of creating additional interest and opportunities and championing this, and other, success stories of ISS and LEO commercialization. For the first time, a technical review meeting was held on February 3, 2014 at NASA Ames Research Center bringing together microgravity and terrestrial experts in exotic

thttp://fomsinc.com/v1/spacefiber-2/ 


\section{COZMUTA AND RASKY}

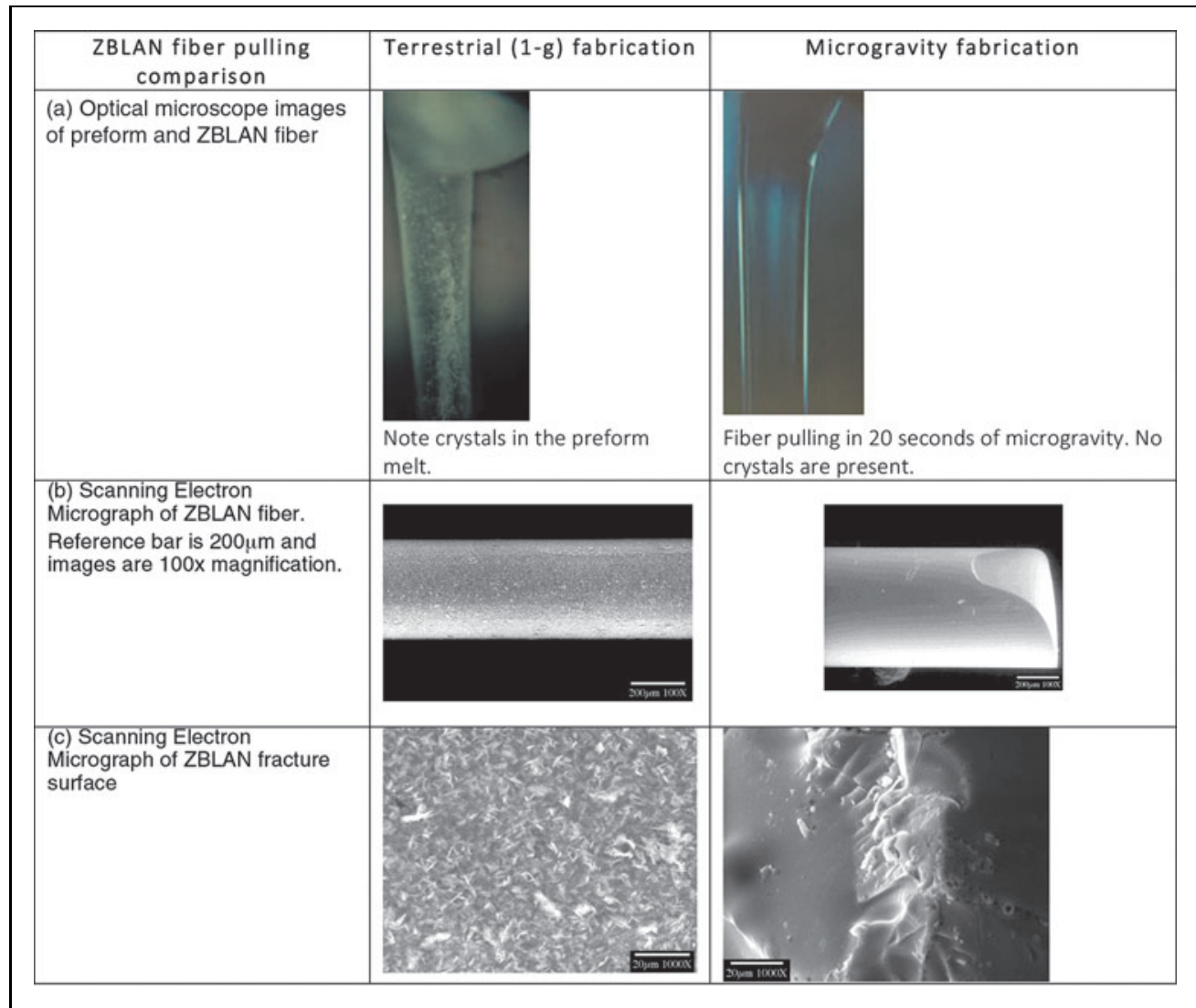

Fig. 13. Images of ZBLAN fibers pulled in 1996 terrestrially and in microgravity on parabolic flights in the same flight unit (Tucker et al., 2004). (a) Optical microscope images of preform and fiber. Note crystallite formation in the preform melt for the fibers pulled terrestrially as opposed to the clarity of the fibers pulled in microgravity. (b) Scanning Electron Micrograph (SEM) of the surface of the ZBLAN fiber (bars represent $20 \mu \mathrm{m}$; images are at $100 \times$ magnification). The fiber surface exhibits smoother appearance when pulled in microgravity. (c) SEM of ZBLAN fracture surface (bars represent $200 \mu \mathrm{m}$; images are at 1,000x magnification). The particles observed on the surface of the terrestrial fiber represent debris from the fracture surface. X-ray diffraction analysis of the ground processed samples indicates that the crystal structure is $\beta-\mathrm{BaZrF}_{6} . \mathrm{SEM}$ of the fracture surface processed in microgravity is purely amorphous (no crystallization observed). distribution of its constituents. In addition, hundreds of uniquely promising fibers handcrafted in Earth's laboratories cannot be manufactured with sufficient yield or quality to support consumer markets.

The future of fiber optics manufacturing in space relies on a synergistic development in both R\&D as well as process and hardware development (Fig. 16). The very first required step is to pull long-length ZBLAN fibers in space by using the best possible preform from the ground, return the spool on Earth, and perform a blind study to achieve a comprehensive characterization of the fiber's properties (from macroscopic properties such as attenuation to microscopic ones, including splicing, surface, and in-depth analysis, through a combination of high-resolution techniques such as XRD, SEM, and TEM). Ideally, the strength and stability of these fibers should also be assessed as a function of time in parallel on the International Space Station (keeping a manufactured fiber spool in space) and on Earth. The reason for the latter is to assess optical fiber manufacturing as well as industry participation representing potential terrestrial demand (see Disclosure). As a result of these efforts, in 2016, NASA awarded two Phase I SBIR grants to Physical Optics Corporation (POC) and Fiber Optics Manufacturing in Space (FOMS, Inc.). The ISS National Laboratory (Center for Advancement of Science in Space) also made an award to FOMS, Inc. to fly the fiber optic manufacturing unit on the ISS. Unexpectedly, Thorlabs partnered recently with Made in Space in an attempt to also manufacture fibers in space.

Today's goals of using the microgravity environment is to improve the transmission quality of ZBLAN and the length of superior quality fiber that can be produced by eliminating sedimentation, clumping of constituents, and crystallization caused by gravity. This might also increase the strength and flexibility of ZBLAN fibers by obtaining a more homogenous any potential degradation that these fibers can incur upon return in a gravitational field. ${ }^{\S}$

Profits could, for example, be maximized by leaving the manufacturing unit in space. Only the preforms and empty spools would be launched, and only the full spool of fiber would be returned to Earth. The in-space manufacturing unit available today is a triple-contained cylinder $\sim 28 \mathrm{~cm}$ (11 inches) in diameter $\times 104 \mathrm{~cm}$ (41 inches) in length. The firstgeneration in-space manufacturing unit has already been built, flight-qualified, man-rated, and successfully flight-tested on the Zero-Gravity parabolic aircraft under an Air Force SBIR. This unit is designed to melt the preform and to pull the fibers to

${ }^{\S} \mathrm{A}$ comprehensive document on standard fiber optics testing is available through The Fiber Optic Association Inc. (www.thefoa.org/tech/ref/contents.html) 


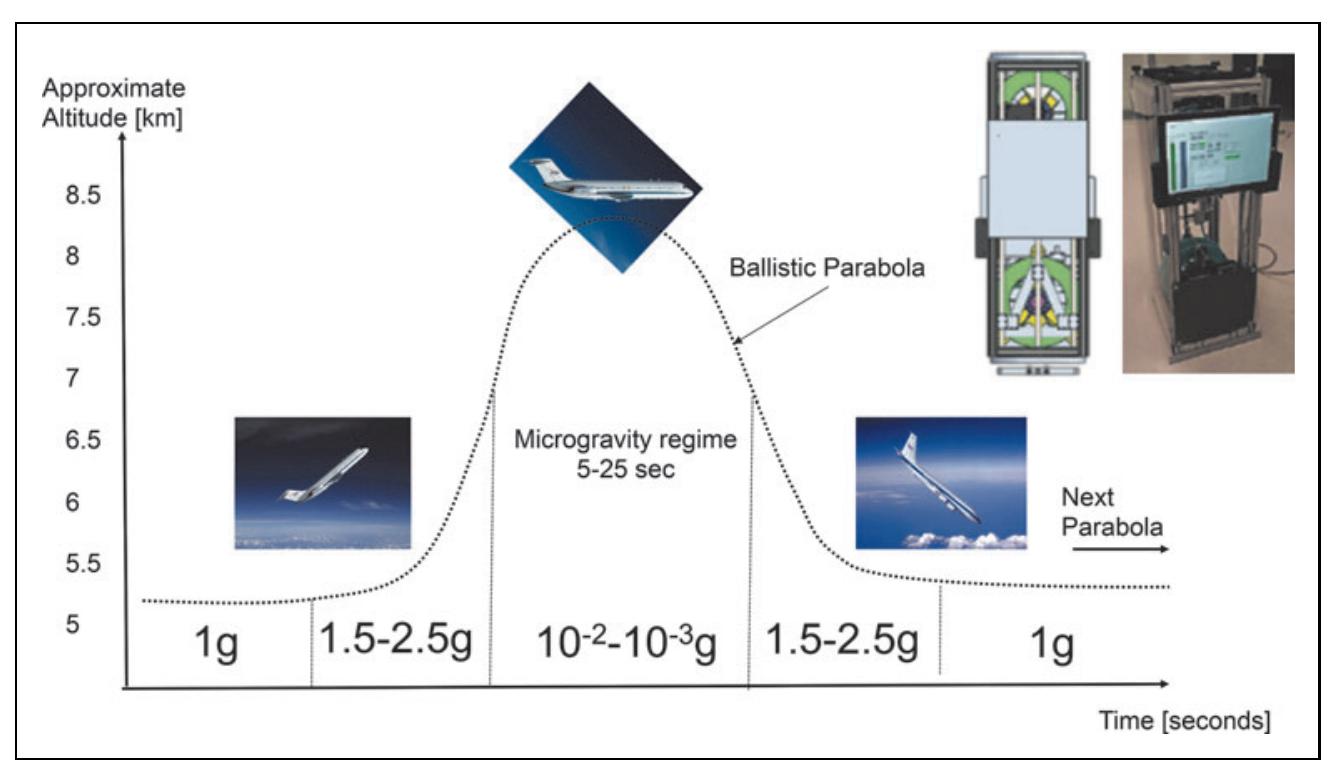

Fig. 14. (left) A typical flight profile for a parabolic flight. The top of the ballistic parabola offers an $\sim 20$ s long window of reduced gravity. The plane usually flies several successive parabolas. (right) FOMS Inc patented microgravity fiber manufacturing prototype unit. This unit has the unique ability to manufacture an estimated $3 \mathrm{~km}$ of exotic optical fiber in microgravity from a $1 \mathrm{~kg}$ preform.
The hardware also needs to be optimized in terms of automation and potentially even teleoperation. Automation would enable independence on very limited and precious astronaut time as well as continuous operation of the manufacturing unit (replacement of preform cassette as well as removal of fiber spool). Other lines of investigations could result in increasing the size of the preform cassette to accommodate larger quantities of preform that would lead to longer length fibers. A reusable, triple-contained, human-rated, flight-qualified, and flight-tested microgravity manufacturing prototype unit exists and can be modified for proofa take-up spool. Approximately $15 \mathrm{~m}$ of high-quality fibers can be produced in $3 \mathrm{~min}$, with an expectation of 12 continuous meters of high-quality fibers from the pull. This can easily be modified to produce multiple kilometers of fibers, because the primary changes are to the preform chamber to hold a longer preform and to the take-up spool to hold kilometer-length fibers.

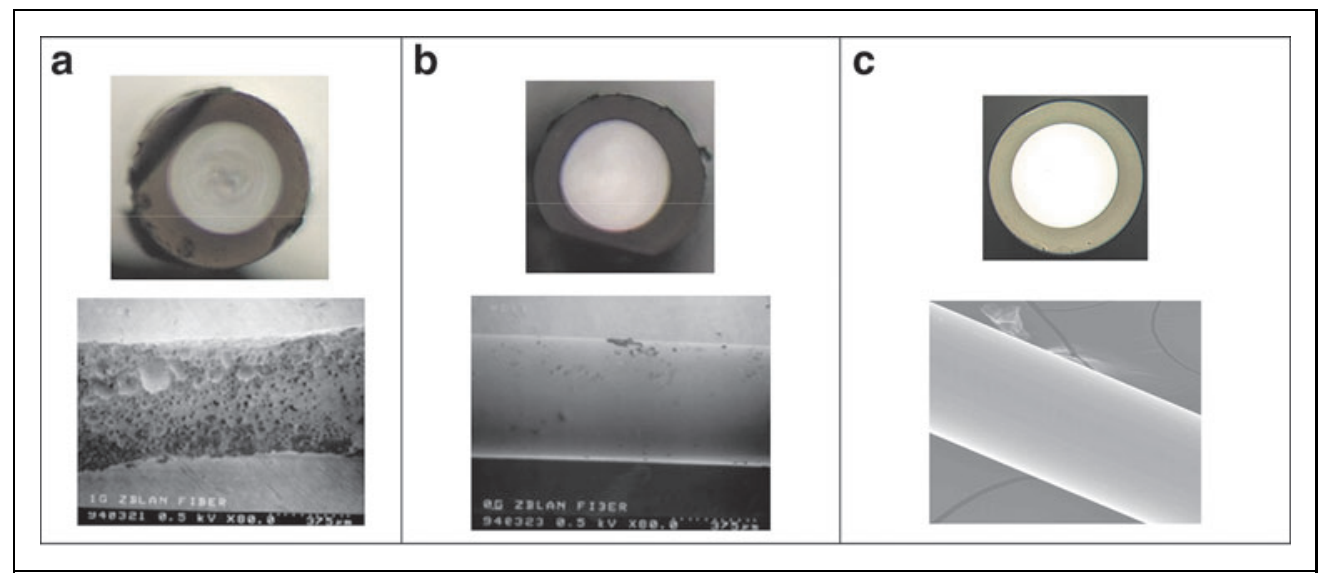

Fig. 15. Top and side view of ZBLAN fibers made in the same unit (a) on ground and (b) on parabolic aircraft through DOD/AirForce 2012 SBIR award. Note that the ZBLAN preform used for (a) and (b) was of average quality since the focus of the flight experiments was more on the optimization of the fiber pulling process. Both (a) and (b) images were processed with high contrast to illuminate defects. (c) Best ZBLAN fiber produced on Earth by Thorlabs. This fiber is of higher quality because it is made of high quality preform optimized under terrestrial laboratory conditions. To also note that the improved quality of the microgravity produced ZBLAN over the terrestrial control was achieved after only three parabolic flights while it took more than two decades of research on Earth to achieve a high quality fiber. FOMS, Inc., holds a trademark on Space Fibers, i.e. fibers pulled in a microgravity environment. of-concept evaluations on the International Space Station within 2 years at relatively low cost (under $\$ 1 \mathrm{M}$ ).

On the REtD side, investigations in microgravity could be focused on making the preform in space (from mixing to melting of the heavy metal powder) to doping of the fibers, manufacturing of hollow fibers and multilayer fibers. The in an end-to-end line of mass production of exotic optical fibers for commercial, government, and medical markets not only to create a better infrastructure for Earth applications but also to support the development of a robust economy in Earth's orbits (orbital data centers, banks, solar currency, communications) that would expand into the Cislunar space and into an entire solar system expansion and settlement.

The range of interests in exotic fiber production and the difficulty in manufacturing these fibers on Earth provide a sound rationale for further government investment in this area. A facility class instrument tested on the commercial zone on ISS could then possibilities are infinite. Ultimately, such a process would result 


\section{EXOTIC OPTICAL FIBERS COMMERCIALIZATION: HISTORY\&FUTURE STEPS}

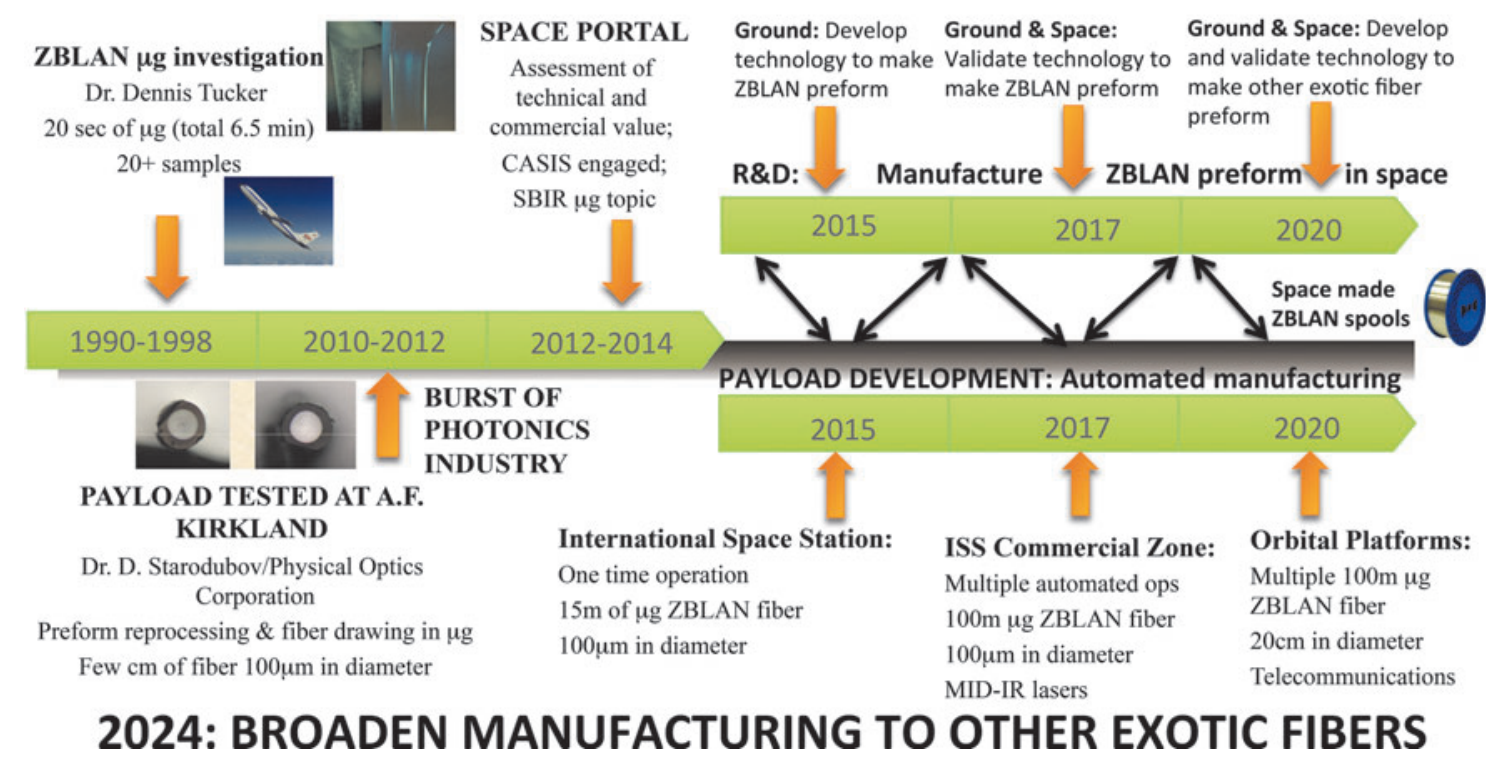

Fig. 16. The future of fiber optics manufacturing in space relies on a synergistic approach by continuing not only the R\&D efforts but also the optimization of the processing and fabrication of the fibers.

open up opportunities beyond, to other commercial platforms (SpaceX DragonLab, Bigelow Aerospace Module, etc.).

\section{ESTIMATING ROI \\ FOR MICROGRAVITY-MANUFACTURED EXOTIC OPTICAL GLASSES AND FIBERS}

Exotic glass fiber production is one of the few areas where the business case for in-space manufacturing could close in the near future. Certain classes of ZBLAN and other exotic fibers are so difficult and expensive to produce on Earth that production in microgravity may be more cost-effective than trying to manage terrestrial manufacturing processes. Very small quantities of materials launched from Earth can yield a high return. This includes the relatively small manufacturing unit (several orders of magnitude reduction in form factor) as well as comparing the resources needed to operate a manufacturing unit on Earth versus space (space solar power, etc.). To note that, in general it is incorrect to think of a manufacturing process in space as a "translational" move of the manufacturing process from Earth. Space manufacturing requires a complete redesign, especially if one wants to make efficient use of local, space resources.

The focus of this study was on terrestrial markets rather than NASA applications, applied rather than basic research, and commercial rather than academic investigators. In evaluating the value of microgravity to the nation's economic growth, both the market value of the microgravity product and the market value of the applications that could result from the microgravity product were considered to gain insight into the conditions that are important for the creation of a robust economy in Earth's orbits and that enable social and economic benefits to the United States. The ISS is the core of the human spaceflight economic ecosystem in orbit and is the primary test-bed for investigating and understanding how to productively work and live in space. In addition to the benefits from microgravity products for terrestrial applications, commercial research and development (RED) enabled by the ISS has implications for the growth of the commercial space economy by helping to develop the customer base for emerging commercial space laboratories, such as those planned by SpaceX (DragonLab) and Bigelow Aerospace.

The return on investment for ZBLAN manufacturing in space can be calculated as follows:

1. Assume a worst-case scenario where both the manufacturing units and the optical glass preforms are launched in a single SpaceX DragonLab and the entire payload is returned to Earth.

2. Assume that the worst-case cost to launch and land the manufacturing unit $=\$ 80 \mathrm{~K} / \mathrm{kg}$.

- This price is chosen because NASA is currently paying SpaceX $\$ 1.6$ billion for the delivery of a 
minimum of $20,000 \mathrm{~kg}$ on 12 flights of the Dragon to ISS and back $\left(\left(\$ 1.6 \times 10^{9}\right) \div\left(20 \times 10^{3} \mathrm{~kg}\right)=\$ 80,000 /\right.$ $\mathrm{kg})$. Current costs for SpaceX's Dragon capsule are expected to drop below $\$ 44 \mathrm{~K} / \mathrm{kg}$ of payload launched and landed.

3. Mass to be launched and landed $=45 \mathrm{~kg}$.

- This is a worst-case scenario where the manufacturing unit is based on today's prototype and no attempt is made to optimize mass or length of fiber produced. The mass of the current in-space manufacturing prototype unit is $\sim 45 \mathrm{~kg}$, including the mass of the preform.

4. Costs to fly a single manufacturing system to space and back $=\$ 3,600,000$.

- Under the worst-case scenario, the flight cost is $45 \mathrm{~kg} \times \$ 80,000 / \mathrm{kg}=\$ 3,600,000$.

5. Value of fibers produced in space in $45 \mathrm{~kg}=\$ 900,000$ to $\$ 21,000,000$.

- Today, custom exotic fibers are sold between $\$ 300 / \mathrm{m}$ and $\$ 3,000 / \mathrm{m}$ (Table 4).

- One kilogram of exotic fiber feedstock (called a "preform") under optimized conditions can produce from 3 to $7 \mathrm{~km}$ of exotic glass fibers in less than an hour.

- At current market prices, a kilogram of preform launched to a fiber manufacturing facility in orbit could yield $3-7 \mathrm{~km}$ of fiber ranging in value from $\$ 900,000$ to $\$ 21,000,000$.

- $3 \mathrm{~km} \times \$ 300 / \mathrm{m}=\$ 900,000$

- $7 \mathrm{~km} \times \$ 300 / \mathrm{m}=\$ 2,100,000$

- $3 \mathrm{~km} \times \$ 3,000 / \mathrm{m}=\$ 9,000,000$

- $7 \mathrm{~km} \times \$ 3,000 / \mathrm{m}=\$ 21,000,000$

- The current low-end market price for ZBLAN fibers is $\$ 150 / \mathrm{m}$. Even at today's lowest market prices, a kilogram of ZBLAN launched into space could be sold on Earth for $\$ 450,000$. Over time, increased availability will result in price reduction.

6. Substantial profits are possible for mid- to high-end products. The estimated value of the exotic fibers manufactured in space from the $45 \mathrm{~kg}$ manufacturing unit ranges from $\$ 900,000$ to $\$ 21,000,000$. Even when the $\$ 3,600,000$ flight costs are subtracted, the midvalue products break even in this scenario. The highend products offer substantial profits.

7. More efficient scenarios offer significantly greater profits of millions of dollars $/ \mathrm{kg}$ of launched material.
- In a more practical scenario, the manufacturing facility would remain in orbit, thereby reducing the launched mass by 95\%. In this scenario, only the preforms and empty spools are launched and only the filled spools are returned (estimated $2 \mathrm{~kg}$ each way).

- Given a nominal cost of $\$ 44,000$ for a payload launched and landed by using the full DragonLab capacity of $3,000 \mathrm{~kg}$, the cost for delivery and return of the manufactured product would be $\$ 88,000$ for the $2 \mathrm{~kg}$ preforms and spools.

- The value of the exotic fibers manufactured in space would remain the same, except that now the value of the product is $\$ 900,000 / \mathrm{kg}$ to $\$ 21,000,000 / \mathrm{kg}$ of preform launched.

The analysis just provided does not take into account the revenues generated by the end-use applications of these glasses and fibers or the value to the public in defense and medical applications. These applications aggregate to form a growing market that currently generates $>5$ billion dollars per year.

\section{CONCLUSIONS}

With the increased demand of terrestrial markets (Internet, telecommunications, etc.) for photonics applications underlying the rise of the global photonics market of which exotic optical fibers and glasses are the main platform material and the evident limitations of current materials, there is a pressing need to develop and manufacture high-performance materials that meet these specific needs (low signal attenuation, broadband expanding into the IR, fast data transmission speed). ZBLAN and other exotic glasses have broad optical transmission windows extending from the ultraviolet to the mid-IR region of the electromagnetic spectra and beyond, with low transmission losses providing unique bandwidth coverage. The unique signal transmission efficiency of exotic optical fibers, particularly in the mid-IR region, is most important for the needs identified for photonics applications (defense, sensors, medical applications, etc.).

One of the major findings from this study is that the commercial potential of the broad field of exotic glass fiber manufacturing could be expanded and, in some cases, enabled by microgravity REtD, and possibly by in-space manufacturing. If successful, the resulting improvements could lead to billions of dollars of new market applications and could significantly impact the global economy over the next 5 years.

Even with the best techniques used today, obtaining terrestrially long lengths of exotic glasses is either not possible to produce or prohibitively expensive, and this restricts the range of possible applications. The quality of many of the 
exotic fibers produced in laboratories and needed for new applications still falls short of the market needs. To a significant degree, these problems are caused by gravity.

Proof-of-concept demonstrations in microgravity (i.e., fibers of sufficient lengths need to be produced to result in proper characterization of attenuation properties) are necessary to determine whether the quality and yield of ZBLAN or other exotic fibers produced in microgravity are good enough to overcome the difficulty and expense of in-space manufacturing. It is likely to take several flights before all of the in-space manufacturing details are mastered and regular production runs can be established. Since, through medical and healthcare applications, this technology also offers a significant public value, exotic glasses and fibers are areas where it would be appropriate for the government to enable a program of applied RED in a facility class instrument maintained on the International Space Station National Laboratory and commercialized beyond. Given the small mass needed for a high return in the production of exotic glass fibers in microgravity, this is the strongest case that the authors have found to date for in-space manufacturing over the next decade.

The authors, however, would like to caution that proving the superior performance of the exotic optical fibers that are manufactured in microgravity is only 1 aspect of the problem that needs to be addressed. For the business case to close, the government needs to consider supporting the viability of manufacturing scale-up to ensure that market-appropriate production volumes can be generated. This latter consideration very much relies on a fundamental shift from the traditional "technology maturation" approach to an "economic maturation" approach. ${ }^{7}$ The ultimate goal of the Technology Readiness level is to mature a technology from a fundamentally new idea to incorporation and efficient use into a system. On the contrary, to advance on an Economic Readiness Level, the technology itself may not necessarily need to mature but the understanding of its economic potential does. The path to economic maturation requires pivoting from the technology maturation approach once a minimum viable product is identified and pursuing a "scale-up" or take-to-market approach that is focused on raising the bottom line.

Doing business in space is rapidly becoming more reliable, affordable, and accessible. From 2010 to 2015, launch prices went down by a factor of $\sim 10$ or more, to about $\$ 5,000 / \mathrm{kg}$ whereas investments into "New Space" companies and technologies are closing in on $\$ 2.5$ billion. With several commercial suppliers operational or on the rise (SpaceX, Orbital ATK, Blue Origin, Sierra Nevada Corp, etc) to Earth's orbits, mission services are improving dramatically. Moreover, private space companies (SpaceX Reusable Dragon Lab; Bige- low's B330) are also scouting the opportunities of renting or selling modules as platforms for orbital free-flying facilities, modules that can be used for automated fabrication to manned experiments. Planetary Resources and Deep Space Industries are the frontrunners in extra-planetary mining (such as asteroids), spurring a modern-day gold rush for raw materials "to fuel exploration in space and prosperity on Earth" with the hope of opening a trillion-dollar industry. These raw materials would also constitute the source of the "space" value chain for space manufacturing. Such segments are nascent; whereas the more established ones revolve around satellite delivery and operation, remote sensing, imaging/data from space, small satellites, etc. since these verticals have so far proved to be the most viable from a business perspective. It is undoubted that the current landscape of Emerging Space companies $^{8}$ is vibrant, fast paced, and rolling beyond the "point of no return." Beyond these emerging verticals, the more "distant" ones such as Space-Based Energy, In-Space Services, Microgravity Research, and Space Resources are still being viewed as falling under the governments' role since "its policy is more of a challenge for New Space companies' growth than any other business aspect." ${ }^{\prime 9}$

\section{ACKNOWLEDGMENTS}

This effort was a true team effort. It would not have been possible without the tremendous dedication, technical and business insights of Lynn D. Harper, Bruce Pittman, and Mark Newfield, founders and members of the Space Portal Office at NAS Ames Research Center. This collaboration extends to other NASA centers, other government agencies, academic institutions, and the private sector. The authors are grateful to Dr. Dennis Tucker (MSFC) for pioneering the work of ZBLAN drawing in microgravity on parabolic flights and for his active participation and valuable guidance and technical review. Many thanks are due for the open exchange and participation to Dr. Dmitry Starodubov of FOMS, Inc., PI of ZBLAN microgravity experiments on Air Force/DOD zero-g parabolic flights, the first to fabricate optical fibers/ZBLAN in microgravity. The authors acknowledge Dr. Jeffrey Ganley, DOD; Dr. William Brooks (expert on communications systems); Dr. David Huntsman, NASA/ MSFC; Edgar Zapata, NASA/KSC; and William Powell (retired NASA). They extend their gratitude to Steve Rubin, senior VP of Strategic Partnerships \&t Alliances of Diginome, Inc; Alan Lee, corporate VP of REtD for AMD (Advanced Micro Devices); and Ron Goedendorp, Nanoracks, for the commercialization, business and market insights, especially during the technical interchanges hosted at the Space Portal, NASA Ames Research Center. They are grateful to Dr. Alexander MacDonald at NASA HQ for his support. 


\section{AUTHOR DISCLOSURE STATEMENT}

No relevant financial interests exist.

The "Exotic Optical Glasses and Fibers" case study was conducted by Dr. Ioana Cozmuta of Science and Technology Corporation between 2013-2014. This study was identified by Dr. Cozmuta as having an unusually high potential for commercial in-space manufacturing. The in-depth investigation of the subject was based on a broad survey of the literature (microgravity, material science, photonics, fiber optics, etc) as well as hundreds of interviews with PI from academia and high-tech business executives. Invited/attending the technical review on February 3, 2014 were Dr. Dmitry Starodubov of FOMS; Dr. Mohammad Saad of Thorlabs; Alan Lee of Advanced Micro Devices (AMD); Steve Rubin of Diginome Inc. To note that prior to this meeting Dr. Saad has not participated in any previous microgravity research and had not considered space flight for commercial RetD of exotic glass fiber products.

A later meeting also held at the Space Portal (April 2014) to further evaluate the costs and opportunities of exotic optical fibers and glasses for commercial RAD in space included Justin Kugler of CASIS (currently at Made in Space); Rich Pournelle of Nanoracks and Denis Tucker of NASA MSFC. A market and economic report was published and distributed at the time. It is to the author's knowledge that a successful commercialization of this case study has the potential to result in creating successful business opportunities that could be valued in $\$ b n$.

\section{REFERENCES}

1. Photonics Market-Global Industry Analysis, Size, Share, Growth, Trends and Forecast, 2014-2020. Transparency Market Research, 2016. www.transparency marketresearch.com/photonics-market.html (Last accessed on Aug 28, 2017).

2. Photonics Market by Application (Display, Photovoltaic, Lighting, Manufacturing Technology), End-use Industry (Building \& Construction, Media, Broadcasting \& Telecommunication, Consumer \&t Business Automation, Medical, Industrial)Global Forecasts to 2021. Markets and Markets, Market Report, 2016. www.marketsandmarkets.com/Market-Reports/photonic-market-88194993.html (Last accessed on Aug 28, 2017).

3. Baer T, Schlachter F. 2010. Lasers in science and industry: A report to OSTP on the contribution of lasers to American jobs and the American economy. www.laserfest.org/lasers/baer-schlachter.pdf (Last accessed on Aug 28, 2017).

4. Goldman Sachs. Profiles in innovation: space, the next investment frontier. www .goldmansachs.com/our-thinking/podcasts/episodes/05-22-2017-noah-poponak .html (Last accessed on Aug 28, 2017).

5. OECD, Directorate for Science, Technology and Industry. The space economy at a glance 2011. https://www.oecd.org/sti/futures/space/48301203.pdf (Last accessed on Aug 28, 2017).

6. Zimmerman R. Capitalism in space: private enterprise and competition reshape the global aerospace launch industry. http://behindtheblack.com/ behind-the-black/essays-and-commentaries/capitalism-in-space-private-enterpriseand-competition-reshape-the-global-aerospace-launch-industryl (Last accessed on Aug 28, 2017).
7. Cozmuta I. Building Blocks of a robust economy in Earth's orbit: The Machinery of Commercialization. In: 67th International Astronautical Congress (IAC), Guadalajara, Mexico, 26-30 September, 2016.

8. Emerging Space: The Evolving Landscape of 21st Century American Spaceflight. NASA Office of Chief Technologist, Alexander MacDonald, 2014. www.nasa.gov/ sites/default/files/files/Emerging_Space_Report.pdf (Last accessed on Aug 28, 2017).

9. "Verticals of New Space," Richard M. David, Thruster, New Space Global, 2014.

\section{SUGGESTED READING}

Aggarwal ID, Harbison BB. Hot Isostatic Pressing of Fluoride Glass Materials. US Patent number 5,078,768, 1992.

Alred GJ, Brusaw CT, Oliu WE. Handbook of Technical Writing, 7th ed. New York: St. Martin's, 2003

An excellent tutorial discussing silica fibers versus future needs for new glasses. http:// ceramics.org/ceramic-tech-today/manufacturing/video-rethinking-optical-fiber-andits-contribution-to-a-7-5-trillion-industry (Last accessed on Aug 28, 2017).

Anselm L, Frischat GH. Early crystallization stages in a heavy metal fluoride glass prepared under normal and weightless conditions. Phys Chem Glasses. 2000;41:32-37.

Ballato J, Dragic P. Rethinking optical fiber: New demands, old glasses. J Am Ceram Soc. 2013;96(9):2675-2692.

Bansal NP, Bruce AJ, Doremus RH, Moynihan CT. Crystallization of fluorozirconate glasses. Mat Res Bull. 1984;19:577-590.

Berg S, Kroger R, Rath HJ. Measurement of extensional viscosity by stretching large liquid bridges in microgravity. J Non-Newtonian Fluid Mech. 1994;55:307.

Berkey GE, Chu PW, Crossland CE, Moore LA, Oi G, Solosky JW. Method of Making a Glass Preform. US Patent number 6,418,757, 2002.

Bocko PL, Thompson DA, Wein, WJ. Methods for Making Sodium-Containing Glass. US Patent number 4,645,524, 1987

Brief overview of ZBLAN http://en.wikipedia.org/wiki/ZBLAN

Busswell AM, Maycock RL, Rhodebush WH. Infrared absorption studies X: The IR absorption of $\mathrm{HF}$ in the vapor state and in solution in an inert solvent. J Chem Phys. 1940;8:362-368.

deleede $G$, deWaat $H$, Hakkens F. Nucleation in ZBLAN glasses. J Amer Cer Soc. 1989;72, 10:1991-1992.

Drehman AJ. Crystallite formation in fluoride glasses. Mat Sci Forum 1987;19-20, 2:483-489.

Tucker DS. Eliminating Crystals in Non-Oxide Optical Fiber Preforms and Optical Fibers. NASA. http://ntrs.nasa.gov/archive/nasa/casi.ntrs.nasa.gov/20120016709.pdf

Elyamani A, Pafchek R. Rutgers University, Fluoride glasses and methods for making optical fibers from the glasses.US Patent 5285518 A, 1994.

Exotic Optical Fibers and Glasses: Technical, market and economic analysis. ESO, Space Portal Report, NASA Ames Research Center, April 2014.

Fjeldly TA, Hordvik A, Drexhage MG. Stability of IR transparent fluoride glasses in humid air studied by Auger electron spectroscopy. Mat Res Bull. 1984;19:685-691.

France PW, Carter SF, Williams JR, Beales KJ, Parker JM. OH absorption in fluoride glass infrared fibers. Electron Lett. 1984;20:607-608.

Freitas AMB, Landgraf FJG, Nyvlt J, Giulietti M. Influence of magnetic field in the kinetics of crystallization of diamagnetic and paramagnetic inorganic salts. Cryst Res Technol. 1999;34:1239.

Galindo V, Gerbeth G, von Ammon W, Tomzig E, Virbulis J. Crystal growth melt flow control by means of magnetic fields. Energy Convers Manage. 2002;43:309.

Gull SF. Developments in maximum-entropy data analysis. In: Skilling J, ed., Maximum Entropy and Bayesian Methods. Dordrecht, Netherlands: Kluwer Academic, 1989, pp. 53-71.

Handbook of crystal growth: fundamentals - edited by Tatau Nishinaga, U. of Tokyo, Japan; Elsevier; 2nd edition; 2014.

Hanson KM. Introduction to Bayesian image analysis. In: Image Processing, M.H. Loew, ed. Proc. SPIE 1898, 1993, pp. 716-731.

Harrington JA. Infrared Fiber Optics. Ceramic \& Materials Engineering Rutgers University Piscataway, NJ 08854-8065. Adapted from an article in the Handbook of Optics, Optical Society of America. Vol. III. McGraw Hill. 2010. ISBN: 9780071498913. 


\section{COZMUTA AND RASKY}

Harris A, et al. Free-space optical wavelength diversity scheme for fog mitigration in a ground-to-unmanned-aerial-vehicle communications link. Opt Eng. 2006;45(8): 086001.

Hewak DW, Mairaj MKA. Optical Waveguides and Optical Fiber Preform including Gallium, Lanthanum, Sulfur, Oxygen and Fluorine. US Patent number 7,016,593, 2006.

http://optics.org/news/4/2/7

http://patents.justia.com/inventor/mohammed-saad and http://proceedings.spiedigit allibrary.org/proceeding.aspx?articleid=1338465

http://quest.arc.nasa.gov/space/teachers/microgravity/emat.html

http://quest.arc.nasa.gov/space/teachers/microgravity/dfluid.html

http://quest.arc.nasa.gov/space/teachers/microgravity/MGprim.html

http://webcache.googleusercontent.com/search?q=cache:5Thtq860Ko0J:www.nasa .gov/pdf/501343main_Microgravity_Science.pdf+\&tcd=1\&thl=en\&tct=clnk\&tgl=uS http://wintergreenresearch.com/reports/Midir.htm

Ishikawa S, Ohga Y, Tsuchiya I, Kanamori H, Yokota H, Kyoto M. Process for Thermal Treatment of Glass Fiber Preforms. US Patent number 5,306,322, 1994.

Kopylov N, Kortan AR. Lucent Technologies Inc, Method for making optical fiber preforms and optical fibers fabricated therefrom. US Patent number $5573571 \mathrm{~A}$, 1996.

Kopylov N, Kortan AR. Method of Eliminating Light Scattering Bubbles in Optical Fiber Preforms. US Patent number 5,776,222, 1998.

Lecoq A, Poulain MJ. Fluoride glasses in ZrF4-BaF2-YF3-AIF3 quaternary system. Non-Cryst Solids. 1980;41:209-213.

Market for fiber optics sensors to hit $\$ 4$ bn by 2017. http://optics.org/news/4/6/17

Metropolis $\mathrm{N}$, et al. Equations of state calculations by fast computing machine. J Chem Phys. 1953;21(6):1087-1091.

Mitachi S, Miyashita Y. Preparation of low-loss fluoride fibers. Electron Lett. 1982;18:170-171.

Mitachi S, Terunauma Y, Ohishi Y, Takahashi S. Reduction of impurities in fluoride glass optical fibers. Jpn J Appl Phys. 1983;22:L537-L538.

Mollenauer LF, Simpson JR, Walker KL. Fabrication of doped filament optical fibers. US Patent number 5,059,230, 1991.

NASA Physical Sciences Research Division, Annual Report, 2003.

National Research Council. Optics and Photonics: Essential Technologies for Our Nation. Washington, DC: The National Academies Press, 2013.

Nice ML. Apparatus and Process for Fiberizing Fluoride Glasses using a Double Crucible and the Compositions Thereby. US Patent number 4,897,100, 1990.

Optics and Photonics: Essential Technologies for Our Nation Committee on Harnessing Light: Capitalizing on Optical Science Trends and Challenges for Future Research; National Materials and Manufacturing Board; Division on Engineering and Physical Sciences; National Research Council. ISBN 978-0-30926377-1. www.nap.edu/catalog.php?record_id=13491

Pan B, Shang D-Y, Li BQ, de Groh HC. Magnetic field effects on g-jitter induced flow and solute transport. Intern J Heat Mass Transfer. 2002;45:125.

Parker JM, Seddon AB, Clare AG. Crystallization of ZrF4-BaF2-NaF-AlF3-LaF3 glasses. Phys Chem Glasses. 1987;28, 1:4-10.

Perelman LC, Paradis J, Barrett E. Mayfield Handbook of Technical and Scientific Writing. Mountain View, CA: Mayfield, 1997.

Petisce JR. Methods and Apparatus for Increasing Optical Fiber Draw Speed. US Patent number 5,314,519, 1994.

Poulain M. Flouride glass fiber sources: Problems and prospects. 2010. www.dtic.mil/cgi-bin/GetTRDdoc?AD=ADA582618
Poulain M. Poulain M, Lucas J, Brun P. Verres Fluores au Tetrafluore de Zirconium Proprities Optiques d'un Verre Dope au Nd(3+). Mat Res Bull. 1975;10:243-246.

Sanghera JS, Aggarwal ID, ed. Infrared Fiber Optics. May 14, 1998 | ISBN-10: 0849324890 | ISBN-13: 978-0849324895. p. 79.

Sanghera JS, Busse LE, Aggarwal ID, Rapp C. Fluoride glass-based fibers. In: Sangherra JS, Aggarwal ID, eds. Infrared Fiber Optics, 1st ed. Boca Raton, Florida: CRC Press, 1998, pp. 75-142.

Torres A, Ganley J, Maji A Tucker D, Starodubov D. Increasing the working temperature range of ZrF4-BaF2-LaF3-AlF3-NaF glass through microgravity processing. Opt Eng. 2014;53(3):036103.

Tran DC. Silver Springs, MD: Infrared Fibers Systems Inc.

Tran DC, Siegel GH, Bendow B. Heavy metal fluoride glasses-A review. J Lightwave Technol. 1984;LT-2(5):566-586.

Tucker DS, Effects of gravity on processing heavy metal fluoride fibers. J Mater Res 1997;12(9):2223-2225.

Tucker DS, Ethridge EC, Smith GA, Workman G. Effects of gravity on ZBLAN glass crystallization. Ann N Y Acad Sci 2004;1027:129-137.

Tucker DS, LaPointe MR. Eliminating Crystals in Non-Oxide Optical Fiber Preforms and Optical Fibers. US Patent 7,848,606 B1, 2010 (Aug 28, 2017).

Tucker DS, LaPointe MR, Jia Z. The effects of a magnetic field on the crystallization of a fluorozirconate glass. J Mat Res. 2007;22(6):1431-1434.

Varma S, Prasad SE, Murley I, Wheat TA, Abe K. The role of statistical design in microgravity materials research. Proc Spacebound 1991;91:248-249.

Varma S, Prasad SE, Murley I, Wheat TA, Abe K. Microgravity processing of fluorozircanate glasses aboard CSAR-1: Preliminary results. Proc Spacebound 1992;92:109-114.

www.prweb.com/releases/fiber_optic_components/fiber_optic_couplers/prweb11386994 .htm

www.rp-photonics.com/fluoride_fibers.html

www.rp-photonics.com/rare_earth_doped_fibers.html

www.sbir.gov/sbirsearch/detail/384437 and http://opticalengineering.spiedigit allibrary.org/article.aspx?articleid $=1850239$

www.spacex.com/about/capabilities

www.dsto.defence.gov.au/attachments/Fact-Sheet-DIRCM_1.pdf

www.nap.edu/catalog.php?record_id $=13491$

www.nasa.gov/home/hqnews/2008/dec/HO_C08-069_ISS_Resupply.html

www.rp-photonics.com/rare_earth_doped_fibers.html

www.nap.edu/catalog.php?record_id=13491

www.rp-photonics.com/rare_earth_doped_fibers.html

www.rp-photonics.com/high_power_fiber_lasers_and_amplifiers.html

www.ncbi.nlm.nih.gov/pubmed/15644351

Zhu X, Peyghambarian N. High-Power ZBLAN Glass Fiber Lasers: Review and Prospect. Adv Optoelectron, 2010;2010:501956, 23 pages.

Address correspondence to:

Ioana Cozmuta

Science and Technology Corporation

Space Portal

NASA Ames Research Center

Moffett Field, CA 94035

E-mail: ioana.cozmuta@nasa.gov 